\title{
PLANIFICACIÓN Y GESTIÓN DE LA CAZA EN MALLORCA. EL VISOR DE ESPACIOS CINEGÉTICOS DEL CONSELL DE MALLORCA
}

\author{
ANTONI BARCELÓ ADROVER ${ }^{1}$, BARTOMEU SEGUÍ CAMPANER ${ }^{2}$, \\ FRANCISCO GUAITA MAS ${ }^{3}$ \\ ${ }^{1}$ Dirección Insular de Relaciones Institucionales y Proyectos Departamento de Presidencia del \\ Consell de Mallorca. Palau Reial,1, 07001 Palma de Mallorca, España \\ ${ }^{2}$ Servei de Caça del Consell de Mallorca. \\ C/General Riera 111, 07010 Palma de Mallorca, España \\ ${ }^{3}$ Oficina Smart, Dirección Insular de Modernización y Transparencia. Departamento de Presidencia. \\ Consell de Mallorca. General Riera 113, 07010 Palma. Illes Balears. España \\ ${ }^{1}$ anbarcelo@conselldemallorca.net, ${ }^{2}$ bsegui@conselldemallorca.net, \\ ${ }^{3}$ fguaita@conselldemallorca.net
}

\section{RESUMEN}

La caza acredita un importante seguimiento social en Mallorca que, en términos territoriales, se traduce en la existencia de una importante superficie gestionada para el uso cinegético. Se presentan las principales características y particularidades de la caza en Mallorca para ir centrando la atención en los espacios cinegéticos y no cinegéticos. La intensa parcelación junto a la elevada cantidad de terrenos acotados requiere de una definición precisa de los límites de las diferentes figuras comprendidas en la Ley de Caza. En este sentido, el visor de espacios cinegéticos del Consell de Mallorca, previa digitalización de todos los cotos de caza y refugios de fauna, supone una innovadora fuente de información territorial y una valiosa herramienta de planificación y gestión cinegética. A partir de aquí, se exponen los resultados de los seis primeros años de actividad y seguimiento de las visitas digitales al visor, sus principales puntos fuertes, las mejoras introducidas y cuestiones de operatividad futura.

Palabras clave: caza; Mallorca; cartografía; visor de espacios cinegéticos; planificación.

\section{PLANNING AND MANAGEMENT OF HUNTING IN MALLORCA. THE VIEWER OF HUNTING SPACES OF THE CONSELL DE MALLORCA}

\section{ABSTRACT}

Hunting has an important social monitoring in Mallorca that, in territorial terms, means an important surface managed for hunting use. Main characteristics of game in Majorca are presented 
Barceló Adrover, A., Seguí Campaner, B., Guaita Mas, F. (2020): “Planificación y gestión de la caza en Mallorca. El visor de espacios cinegéticos del Consell de Mallorca", GeoFocus, $n^{\circ}$ 25, p. 121-151. http://dx.doi.org/10.21138/GF.660

to focus attention on hunting and non-hunting spaces. The intense parceling together with the high number of bounded terrains requires a precise definition of the limits of the different figures included in the Hunting Law. In this sense, the viewer of hunting spaces of the Consell de Mallorca, after digitization of all hunting areas and wildlife refuges, is an innovative source of territorial information and a valuable tool for planning and hunting management. From here, the results of the first six years of activity and monitoring of the digital visits to the viewer, its main strengths, the improvements introduced and questions of future operability are exposed.

Keywords: hunting; Mallorca; cartography; viewer of hunting spaces; planning.

\section{Introducción: La caza en Mallorca y los espacios cinegéticos}

España es uno de los principales exponentes de la actividad cinegética en el contexto europeo. Así lo refrendan aspectos como el elevado número de cazadores, la gran superficie destinada a aprovechamiento venatorio o el amplio abanico de especies cinegéticas (Barceló, Grimalt y Binimelis, 2017). En este sentido, el $87 \%$ del territorio español está declarado como de aprovechamiento cinegético, en 2013 se expidieron 848.243 licencias de caza y en términos socieconómicos la actividad venatoria moviliza en España 5.470 M. de euros de gasto anual, contribuye al mantenimiento de 186.758 empleos anuales y, en su conjunto, genera el 0,3\% del PIB del país. Desde la vertiente conservacionista, la caza es reconocida como una herramienta de gestión de la fauna silvestre y de los ecosistemas, ya sea mediante programas de conservación de especies, actividades orientadas a sensibilizar y concienciar sobre la necesidad de cazar de manera responsable y sostenible, o aplicando medidas de gestión agroambientales (Andueza et al., 2018).

En 2013, en la Comunidad Autónoma de las Islas Baleares, según datos del Ministerio de Agricultura, Pesca y Alimentación, se expidieron 14.188 licencias de caza (esta cifra hace referencia al total de licencias expedidas no al total de vigentes, ya que existen licencias para uno, dos o tres años) y en torno al $75 \%$ de la superficie se corresponde con terrenos cinegéticos. En el año 2010 se traspasaron desde la Administración de la Comunidad Autónoma de las Islas Baleares a los diferentes Consejos Insulares, las funciones y los servicios inherentes en materia de caza y de regulación, vigilancia y aprovechamiento de los recursos cinegéticos, además de pesca fluvial. Así las cosas, el Departamento de Promoción Económica y Desarrollo Local del Consell de Mallorca ejerce actualmente las funciones y servicios inherentes a las competencias en materia de caza en la Isla de Mallorca. Según datos del Servei de Caça, en el año 2017, se encuentran en activo en la isla un total de 16.317 titulares de licencia de caza $(1,88 \%$ de la población total) y $280.990,41$ ha se corresponden con espacios cinegéticos $(77,63 \%$ del total de la superficie insular) (Barceló et al., 2018).

Mallorca constituye un espacio insular del Mediterráneo occidental con un amplio bagaje cinegético, entre otras cuestiones, por la variedad de especies de caza menor beneficiada por una privilegiada posición geográfica en rutas migratorias, por la diversidad de hábitats y por la presencia de una especie de caza mayor única, la cabra salvaje mallorquina, además de razas autóctonas de perros ( $c a$ mè, ca rater y ca eivissenc) y de modalidades tradicionales exclusivas (caza de tords a coll, caza de cabras con perros y lazos, caza de la perdiz con reclamo y bagues y caza con cans eivissencs). Los valores cinegéticos se complementan, por ejemplo, con amplios estudios históricos (Bover y Rosselló, 2016), con una terminología lingüística genuina con argots 
Barceló Adrover, A., Seguí Campaner, B., Guaita Mas, F. (2020): "Planificación y gestión de la caza en Mallorca. El visor de espacios cinegéticos del Consell de Mallorca", GeoFocus, $n^{\circ}$ 25, p. 121-151. http://dx.doi.org/10.21138/GF.660

propios según comarcas (Servera Vila, 2006), con construcciones de piedra en seco específicas para la caza (Aguiló, et al., 2011; Barceló Adrover y Grimalt Gelabert, 2014) o a través de la existencia de un complejo tejido asociacionista repartido por prácticamente todas las demarcaciones municipales (Barcelo, Grimalt y Binimelis, 2015).

Un aspecto clave, indisociable a la actividad cinegética, al ser una activad rural y que además consume mucho espacio (López Ontiveros, 1992) es la preceptiva necesidad de terrenos en los cuales se pueda practicar la caza. En este trabajo abordamos cuestiones relativas a los terrenos cinegéticos, principalmente aquellas relativos a sus características y al uso de nuevas tecnologías relativas a herramientas web que permitan a las personas usuarias visualizar e interaccionar con mapas temáticos específicos.

La Ley 6/2006, de 12 de abril, balear de caza y pesca fluvial, que deriva de la ley de caza nacional de 1970, califica los terrenos en cinegéticos y en no cinegéticos. Son terrenos cinegéticos los cotos de caza, las zonas de caza controlada y los terrenos gestionados de aprovechamiento común. Asimismo, los cotos de caza se clasifican en cotos de sociedades locales, cotos particulares, cotos sociales, cotos públicos y cotos intensivos. Por su parte, son terrenos no cinegéticos los refugios de fauna y las zonas inhábiles de caza.

El dominio de los terrenos cinegéticos (cotos de caza y zonas de caza controlada) sobre los no cinegéticos es muy claro (Tabla 1). De hecho, por cada hectárea no cinegética hay 27,72 ha que se corresponde con cotos de caza o zonas de caza controlada.

Tabla 1. Número y extensión de terrenos acotados (cotos de caza y zonas de caza controlada) y de terrenos no cinegéticos en Mallorca, 2018.

\begin{tabular}{|rr|r|rr|r|}
\hline $\begin{array}{l}\text { Núm. de terrenos } \\
\text { acotados }\end{array}$ & $\begin{array}{l}\text { S. de terrenos } \\
\text { acotados (ha) }\end{array}$ & $\begin{array}{l}\text { Núm. de terrenos no } \\
\text { cinegéticos }\end{array}$ & $\begin{array}{l}\text { Sup. de terrenos no } \\
\text { cinegéticos (ha) }\end{array}$ \\
\hline & 1.500 & $280.990,41$ & & 86 & $10.136,74$ \\
\hline
\end{tabular}

Fuente: Barceló et al., 2018.

A todo lo anterior, hay que añadir los terrenos de régimen cinegético común, popularmente llamados también terrenos libres. Los terrenos libres se deducen por defecto al no ser cotos o zonas de caza controlada, ni refugios de fauna o zonas inhábiles, ni entornos urbanizados. De hecho, la caza en los terrenos de régimen cinegético común queda condicionada a la aplicación del plan marco de ordenación previsto en el artículo 25 del Reglamento 1/2012 del Consell Insular de Mallorca, por la cual se regulan las vedas y los recursos cinegéticos. No obstante, los terrenos libres bien pueden ser cinegéticos (si disponen de plan técnico propio o si el ayuntamiento en cuestión se adhiere al plan marco que elabora anualmente el Consell de Mallorca) o no cinegéticos (si no disponen de planificación cinegética). En el 2013, la superficie considerada de régimen cinegética común ascendía a 51.072,08 ha, lo que supone un 14,11 \% del total insular (Barceló, 2015).

A partir de la superposición de las diferentes capas vectoriales de terrenos cinegéticos, terrenos no cinegéticos y núcleos urbanos se obtiene un mapa de conjunto (Barceló, 2015) que muestra la densa estructuración cinegética y, por defecto, define los terrenos libres (Figura 1). 
Barceló Adrover, A., Seguí Campaner, B., Guaita Mas, F. (2020): "Planificación y gestión de la caza en Mallorca. El visor de espacios cinegéticos del Consell de Mallorca", GeoFocus, $n^{\circ}$ 25, p. 121-151. http://dx.doi.org/10.21138/GF.660

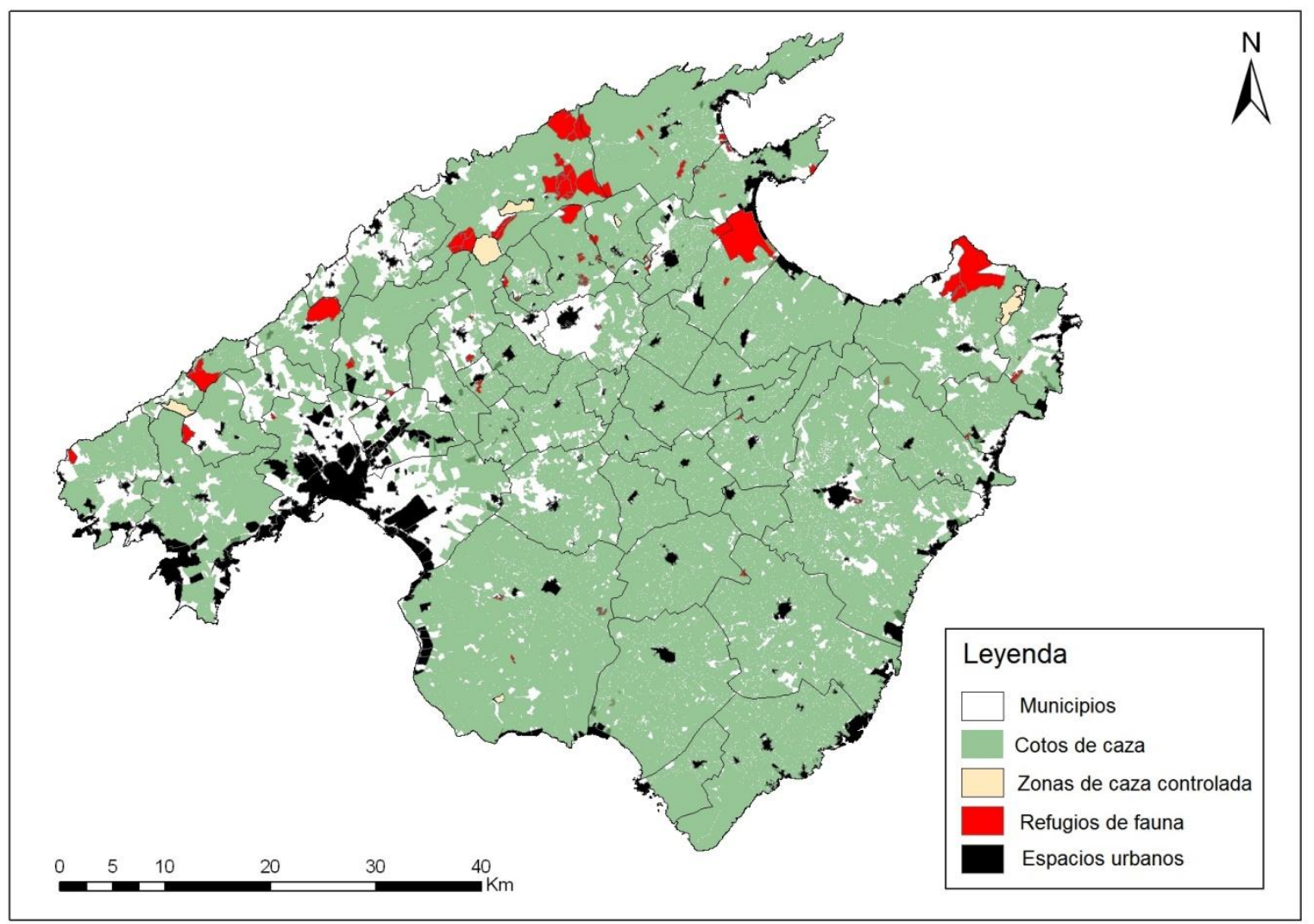

Figura 1. Mapa de espacios cinegéticos y no cinegéticos en Mallorca

Fuente: Barceló, 2015

A raíz de la intensa parcelación y el dominio de la pequeña propiedad en Mallorca (Brunet, 1978; Jover Avellà y Manera Erbina, 2009; Antich y Sancho, 2003) no siempre los límites de los cotos se han mostrado claros y bien definidos, si bien históricamente la legislación sectorial en la materia ha hecho especial hincapié en establecer medios para delimitar correctamente los espacios acotados, en muchas ocasiones de acuerdo con los derechos de propiedad. De hecho, la Ley de Caza de 1902 ya preveía que los vedados debían de disponer de tablillas o piedras con letreros, en sus límites, con la inscripción "Vedado de Caza". Por su parte, en cumplimiento de lo dispuesto en la Ley de Caza de 4 de abril de 1970 y el Reglamento para su aplicación de 25 de marzo de 1971, el Ministerio de Agricultura, mediante la Dirección General de Montes publicó la Resolución por la que se dan normas para la señalización de terrenos sometidos a régimen cinegético especial y de los palomares industriales (BOE, núm. 92 de 17 de abril de 1971). La creación de cotos de caza y de otras figuras de índole cinegética llevan asociadas la generación de cartografía para definir los límites de estos espacios. Los primeros expedientes de creación de cotos en Mallorca derivados de la Ley de 1970, tramitados por el Servicio de Pesca Continental, Caza y Parques Nacionales de la Dirección General de Montes Caza y Pesca Fluvial del Ministerio de Agricultura, presentan sus límites marcados sobre mapas de edición militar a escala 1: 50.000 (Figura 2) acompañados por un informe del cuerpo de la guardería forestal. 


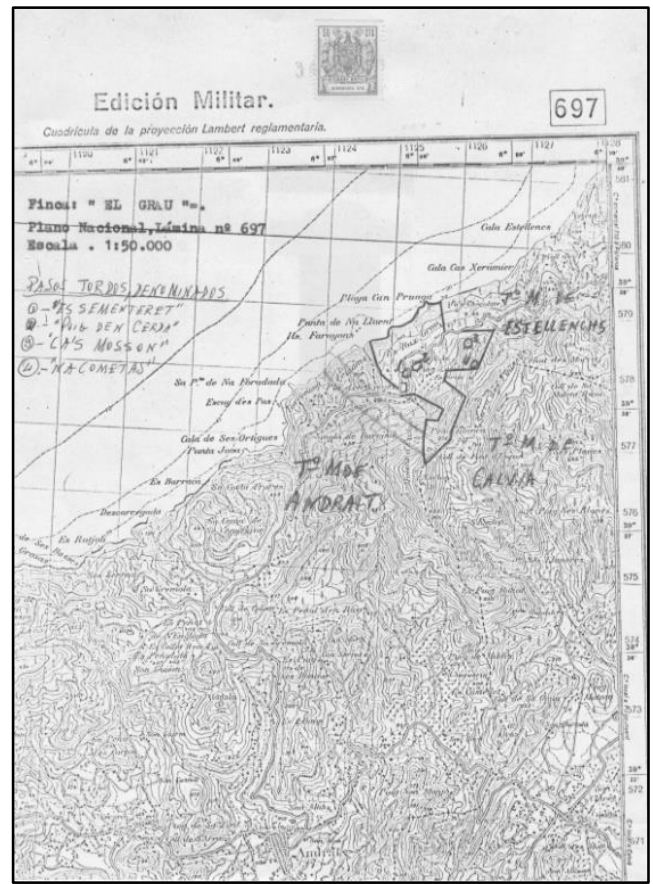

Figura 2. Mapa incluido en un expediente de creación de coto de caza a principios de la década de 1970. La delimitación de la zona acotada se trazaba a mano alzada sobre un mapa militar a escala 1:50.000.

Fuente: Servei de Caça del Consell de Mallorca.

La norma relativa a la ley de 1970 indica que la señalización de los terrenos sometidos a régimen cinegético especial se efectuará con carteles, señales distintivas y rótulos en rocas, muros, tapias, etc., a lo largo de todo su perímetro exterior e incluso interior, en los casos que existan enclavados. La colocación de estos carteles y señales se hará de tal forma que su leyenda o distintivo sea visible desde el exterior del terreno señalizado. Las señales de primer orden o carteles se colocarán necesariamente en todas las vías de acceso que penetren en el territorio en cuestión y en cuantos puntos intermedios sean necesarios para que la distancia entre dos carteles no sea superior a 600 metros. Entre las señales anteriormente citadas se situarán las de segundo orden, con distancias máximas de una a otra de 100 metros. Estas señales de segundo orden consistirán en distintivos normalizados o bien en rótulos pintados en rocas, muros, tapias, etc. Toda la señalización deberá estar colocada de forma tal que un observador situado ante uno de los carteles o señales tenga al alcance de su vista a los dos más inmediatos.

En torno a 1994, la Sección de Caza de la Consejería de Agricultura y Pesca del Gobierno Balear, encargada de tramitar los expedientes relacionados con cotos, incorporó una nueva fuente cartográfica para acompañar los mapas topográficos: el catastro de rústica. A partir de la aportación de datos catastrales de los bienes inmuebles, la cartografía convencional de los terrenos cinegéticos incrementaba su precisión. Paralelamente, la disposición y facilidad de generación de cartografía topográfica a escalas mayores (1: 25.000; 1: 10.000 y 1: 5.000) también contribuía a mejorar la exactitud de los límites de los vedados. 
Barceló Adrover, A., Seguí Campaner, B., Guaita Mas, F. (2020): “Planificación y gestión de la caza en Mallorca. El visor de espacios cinegéticos del Consell de Mallorca", GeoFocus, $n^{\circ}$ 25, p. 121-151. http://dx.doi.org/10.21138/GF.660

Ya en la actualidad, la Ley de Caza Balear de 2006, inicialmente no contempló la variación de los criterios de señalización definidos en la legislación nacional de la década 1970. No obstante, el Reglamento 1/2012 del Consell Insular de Mallorca por el cual se regulan las vedas y los recursos cinegéticos, aprobado definitivamente el día 9 de febrero de 2012 dispone de los artículos 26 y 27 dedicados exclusivamente a la señalización de terrenos, con los siguientes aspectos más destacados:

- Los terrenos cinegéticos que se deben señalizar son los cotos de sociedades locales, cotos particulares, cotos sociales, cotos públicos y cotos intensivos, así como zonas de caza controlada; y los terrenos no cinegéticos que se deben señalizar, son los refugios de fauna.

- Para reducir el impacto visual se deben colocar el mínimo de placas, de acuerdo con criterios de visibilidad, de distancia entre placas y accesos.

- Los terrenos libres quedan señalizados por defecto, de acuerdo con la delimitación perimetral de los cotos colindantes

- La cartografía digital oficial de los terrenos cinegéticos publicada por el departamento de Medio Ambiente del Consell de Mallorca que marca los límites que figuran en los expedientes de los cotos, así como la de los terrenos libres, prevalece por encima de la señalización de campo, a todos los efectos.

- Los titulares de los cotos de caza y de los refugios de fauna han de mantener actualizada la señalización de los terrenos de acuerdo con el expediente correspondiente y con la cartografía digital oficial hecha pública.

Complementariamente, la Ley 3/2013, de 17 de julio, de modificación de la Ley 6/2006, de 12 de abril, balear de caza y pesca fluvial, y modificada por la Ley 6/2007, de 27 de diciembre, de medidas tributarias y económico-administrativas, en su disposición adicional sexta, vuelve a abordar el tema de la cartografía digital en cuanto a la corrección de deficiencias en los expedientes de los cotos. Así, el apartado legislativo en cuestión dispone que, a raíz de la implantación de nuevas tecnologías basadas en sistemas de información geográfica, la administración competente en materia de caza procederá a la corrección de oficio de las deficiencias, inconsistencias y errores materiales en los límites y superficies que puedan existir en los expedientes de cotos. Las correcciones serán vigentes a partir de la fecha de publicación de la cartografía digital oficial. Estas disposiciones normativas suponen un cambio de paradigma en el ámbito de la delimitación de los terrenos de caza, dando mucho valor al uso de medios y herramientas digitales.

Previamente, y a la par con los avances en disponibilidad y formación en el uso de sistemas de información geográfica, la Dirección General de Caza, Protección de Especies y Educación Ambiental del Gobierno de las Islas Baleares empezó, en el año 2005, a digitalizar en formato vectorial los mapas obrantes en los expedientes administrativos de los cotos de caza. Tras varios años de laboriosas tareas de digitalización, trabajos de campo y audiencias a personas interesadas, la información generada se publicó por primera vez en el año 2008 en el visor de la Infraestructura de Datos Espaciales de las Islas Baleares (https://ideib.caib.es/visor/). En el 2010, y con el traspaso de competencias en materia de caza de la Comunidad Autónoma de las Islas Baleares a los Consejos Insulares, los datos espaciales sobre caza siguieron publicándose en la IDEIB vía WMS, aunque en el mes de julio de 2013, el Consell de Mallorca implantó un visor propio de espacios cinegéticos para uso convencional en ordenadores de mesa (http://www.conselldemallorca.info/sitmun/espais cinegetics.jsp) mientras que en el mes de octubre ya fue funcional para dispositivos móviles (https://www2.conselldemallorca.cat/sit/espais_cinegetics/). 
Barceló Adrover, A., Seguí Campaner, B., Guaita Mas, F. (2020): “Planificación y gestión de la caza en Mallorca. El visor de espacios cinegéticos del Consell de Mallorca”, GeoFocus, $n^{\circ} 25$, p. 121-151. http://dx.doi.org/10.21138/GF.660

Con este trabajo se pretende dar a conocer el proceso seguido por el Consell de Mallorca en cuanto a la implantación de visores de espacios cinegéticos, sus diferentes funcionalidades y los principales resultados conseguidos durante 6 años de operatividad.

En función de los antecedentes previos, el artículo se inicia con un repaso del estado de la cuestión sobre el uso de sistemas de información geográfica y visores en el sector de la caza para seguidamente describir el proceso de digitalización de los espacios cinegéticos y no cinegéticos en Mallorca, e implantación de los diferentes visores. Se analizarán en detalle los principales resultados conseguidos entre 2013 y 2019 así como las diferentes funcionalidades derivadas en materia de planificación y gestión cinegética, además de la valoración de mejoras de futuro.

\section{Estado de la cuestión}

Los trabajos académicos específicos sobre caza y cartografía digital en el ámbito nacional son relativamente escasos, si bien cabe destacar tesis doctorales (Pérez Carral, 1997; Jiménez García, 2007) orientadas en la mejora de la gestión de especies de caza mayor y menor utilizando el apoyo de herramientas SIG y artículos multidisciplinares que analizan la evolución de poblaciones cinegéticas (Fernández Manso, Guerra Velasco, Quintano Pastor y Delgado, 2002) o caracterizan los aprovechamientos cinegéticos (Farfán, Guerrero, Real, Barbosa y Vargas, 2004).

En el caso concreto de visores temáticos sobre espacios cinegéticos no se localiza bibliografía específica, aunque se debe mencionar el creciente número de publicaciones asociadas a visores cartográficos que abordan una gran diversidad temática como la gestión del patrimonio cultural (Amaro-Mellado y Antón, 2016), la conservación de especies silvestres (Taborda, Oria y Vázquez, 2018), el conocimiento de espacios de alto valor ambiental (Martín, Alonso y Gomariz, 2011), la identificación e inventario de glaciares rocosos (Ventura, 2016) o análisis de características urbanas (Sancho y Monzón, 2018). En este sentido, el presente trabajo supone una novedosa aportación temática en el campo de la actividad cinegética.

En el ámbito internacional, la Bristish Association for Shooting and Conservation (BASC) con más de 150.000 personas asociadas (BASC, 2017), se erige como principal asociación del Reino Unido que apoya la caza y el tiro, destacando el importante papel que juegan estas actividades en la conservación de la biodiversidad. En este sentido, la BASC dispone del sitio web Green Shots Mapping and Bag Recording (https://basc.org.uk/conservation/green-shoots-mapping/) que permite crear mapas en línea y llevar registros de capturas / censos, además de proporcionar una herramienta mediante la cual las personas que practican la caza puedan contribuir a la conservación de especies y hábitats. The Basc Magazine, Shooting \& Conservation publicó los resultados de una encuesta digital dirigida a los usuarios de la interfaz Green Shots Mapping and Bag Recording (Danby, 2017) con los siguientes principales resultados:

- $\quad$ El $86 \%$ de las personas usuarias recomendaría la herramienta a otras.

- $\quad$ El $86 \%$ de las personas usuarias considera que el sitio web es fácil de usar (el $28 \%$ ha proporcionado asistencia a otras personas por teléfono, web o en persona y el $34 \%$ ha hecho uso de la asistencia en línea, principalmente tutoriales)

- El $80 \%$ contesta que utilizar la herramienta es fácil. Destacan la facilidad de uso, la ayuda que proporciona a planificar la jornada de caza y la definición de los límites de las zonas de caza. 
Barceló Adrover, A., Seguí Campaner, B., Guaita Mas, F. (2020): “Planificación y gestión de la caza en Mallorca. El visor de espacios cinegéticos del Consell de Mallorca", GeoFocus, $n^{\circ}$ 25, p. 121-151. http://dx.doi.org/10.21138/GF.660

- El $88 \%$ no encuentran dificultoso el uso de las funciones que permiten registrar espacialmente los lugares dónde han observado especies de fauna silvestre.

- El $85 \%$ responde que es fácil / no difícil elaborar un resumen de los trayectos o recorridos de caza

- $\quad$ El $67 \%$ encuentra fácil / no difícil elaborar mapas de detallados de las zonas de tiro.

Al objeto de disponer de información detallada sobre uso de visores cartográficos específicos sobre terrenos cinegéticos, el Servei de Caça del Consell de Mallorca, en el marco de una reunión del Comité de Caza y Pesca del Ministerio de Agricultura, Pesca y Alimentación (MAPA) del Gobierno de España en 2017, planteó una breve encuesta al personal técnico de las Comunidades Autónomas de Andalucía, Aragón, Cataluña, Castilla-la Mancha, Galicia, Madrid, Murcia y Navarra. Estas ocho comunidades junto con las Islas Baleares suman más de los dos tercios del total de licencias de caza y más del $60 \%$ del territorio acotado del total nacional en 2016 (MAPA, 2019). Sin contar el caso de estudio, Mallorca, la mayoría de comunidades (75\%) dispone de visores de espacios cinegéticos, si bien son pocas $(25 \%)$ las que disponen también de visores para dispositivos móviles y, en todos los casos coinciden en que la implantación de las infraestructuras de datos espaciales en abierto es reciente (a partir de 2011). Sólo Navarra dispone de normativa específica referente a la prevalencia de la cartografía digital sobre la señalización de campo. En cuanto a la caza en los terrenos libres, se produce el aprovechamiento cinegético como tal (Cataluña y Galicia) o está sujeta a gestión y reconversión a otro tipo de control (Tabla 2).

Tabla 2. Comunidad Autónoma, operatividad de visores cinegéticos, disponibilidad de visores para dispositivos móviles, año de implantación, existencia de normativa específica y posibilidad de cazar en terrenos libres.

\begin{tabular}{|l|l|l|l|l|l|}
\hline Comunidad & $\begin{array}{l}\text { Visor } \\
\text { cinegético }\end{array}$ & Visor móvil & $\begin{array}{l}\text { Año de } \\
\text { implantación }\end{array}$ & $\begin{array}{l}\text { Normativa } \\
\text { específica }\end{array}$ & $\begin{array}{l}\text { Terrenos } \\
\text { libres }\end{array}$ \\
\hline Andalucía & Sí & - & $\begin{array}{l}\text { A partir de } \\
2016\end{array}$ & No & No \\
\hline Aragón & Sí & No & - & No & No \\
\hline Cataluña & Sí & No & $2011-2015$ & No & Sí \\
\hline $\begin{array}{l}\text { Castilla }- \text { La } \\
\text { Mancha }\end{array}$ & No & - & - & No & No \\
\hline Galicia & No & No & - & No & Sí \\
\hline Madrid & Sí & No & $2011-2015$ & No & No (AE) \\
\hline Murcia & Sí & Sí & $\begin{array}{l}\text { A partir de } \\
2016\end{array}$ & No & No \\
\hline Navarra & Sí & Sí & $\begin{array}{l}\text { A partir de } \\
2016\end{array}$ & Sí & No \\
\hline Mallorca & Sí & Sí & 2013 & Sí & Sí \\
\hline
\end{tabular}

Fuente: elaboración propia a partir de encuesta elaborada por el Servei de Caça del Consell de Mallorca

En cuanto al ámbito balear, el Servicio de Información Territorial de las Islas Baleares (SITIBSA) ha participado en diferentes jornadas (junio 2008 jornada del grupo de trabajo de la IDEE; 2008, 2009 y 2010 jornada de información geográfica de las IB, 2011 presentación en Ibiza, 2018 Jornadas Ibéricas de las IDE) para dar a conocer, entre otras cuestiones, la infraestructura de datos espaciales de las Islas Baleares (IDEIB) desarrollada en el marco de la Directiva Europea INSPIRE y de la Infraestructura de Datos Espaciales de España (IDEE) con el objetivo de distribuir 
Barceló Adrover, A., Seguí Campaner, B., Guaita Mas, F. (2020): "Planificación y gestión de la caza en Mallorca. El visor de espacios cinegéticos del Consell de Mallorca”, GeoFocus, $n^{\circ} 25$, p. 121-151. http://dx.doi.org/10.21138/GF.660

y difundir la información geográfica del Gobierno de las Islas Baleares mediante el uso de medios telemáticos.

Por su parte, el Consell de Mallorca presentó su IDE (IDEmallorca) en la Conferencia de Usuarios de ESRI España 2008, es miembro del grupo de trabajo de IDE local (GTIDELocal) de la IDEE y ha participado en diferentes jornadas para dar a conocer la IDEmallorca y el proyecto SITMUN: Jornada del grupo de trabajo de la IDEE 2008, Jornadas de Información geográfica de las Illes Balears 2008 y 2009, Encuentro Diputaciones Barcelona 2009, V Jornadas de SIG libre de Girona 2011, IX Semana Geomática Internacional/GlobalGeo 2011, Jornadas Ibéricas de las IDE 2013 y Jornada EIEL Mallorca 2017.

En referencia a caza y uso de nuevas tecnologías geográficas en publicaciones, el Consell de Mallorca inició su recorrido en el año 2001 en un estudio sobre la alimentación de la marta (Martes martes) en tres parcelas de la localidad de sa Coma Calenta (Término Municipal de Andratx), representativas de los hábitats predominantes de las Sierra de Tramuntana (Ortega et al., 2002). En este trabajo se utilizó un GPS para la determinación UTM de los excrementos de marta y el programa Microstation para su representación gráfica, obteniéndose mapas a escala 1:2.000. Previamente, Seguí y Santandreu (1998) publicaron un resumen del estudio sobre el seguimiento poblacional de los zorzales invernantes en las Islas Baleares y lo acompañaron con mapas temáticos de símbolos proporcionales en relación a capturas por municipios.

Posteriormente, a partir de 2014, el Servei de Caça del Consell de Mallorca, en ocasiones en colaboración con el Departamento de Geografía de la Universidad de les Illes Baleares, inicia una nueva etapa con numerosas publicaciones que incluyen representaciones cartográficas temáticas de cotos, de titulares de licencias de caza o de elementos de piedra en seco con interés cinegético (Seguí et al., 2014; Barceló, Grimalt y Binimelis, 2015; Barceló, 2015; Barceló, Binimelis y Grimalt, 2016; Barceló, Seguí y Rengifo, 2017 y Barceló, Grimalt y Binimelis, 2017 o Barceló, Grimalt y Binimelis, 2018) que parten de las bases de datos geográficas, estadísticas y del trabajo de campo realizado por personal del Servei de Caça. La organización, el mes de mayo de 2019, de la Jornada Recerca $i$ gestió dins l'ámbit cinegétic (Pons et al., 2019) pone de relieve la gran importancia del uso de visores temáticos y de los sistemas de información geográfica en el desarrollo de proyectos de investigación del Servei de Caça del Consell de Mallorca (Muñoz et al., 2019 a; Tejada et al., 2019; Rodríguez-Tejeiro et al., 2019 y Muñoz et al., 2019 b). Además, cabe destacar la elaboración de un mapa comarcal insular elaborado a partir de variables cinegéticas al objeto de facilitar la aplicación integral y efectiva de criterios de gestión y ordenación de la caza, propuesto inicialmente por Barceló (2015) y revisado en una segunda fase por Barceló, Grimalt y Binimelis (2018). El documento definitivo incluye siete comarcas cinegéticas: Llanos, marinas y sierras menores, Cuenca septentrional, Marina, Garrigas y montes, Montaña, Palma y Albufera (Figura 3). 
Barceló Adrover, A., Seguí Campaner, B., Guaita Mas, F. (2020): "Planificación y gestión de la caza en Mallorca. El visor de espacios cinegéticos del Consell de Mallorca", GeoFocus, $n^{\circ}$ 25, p. 121-151. http://dx.doi.org/10.21138/GF.660

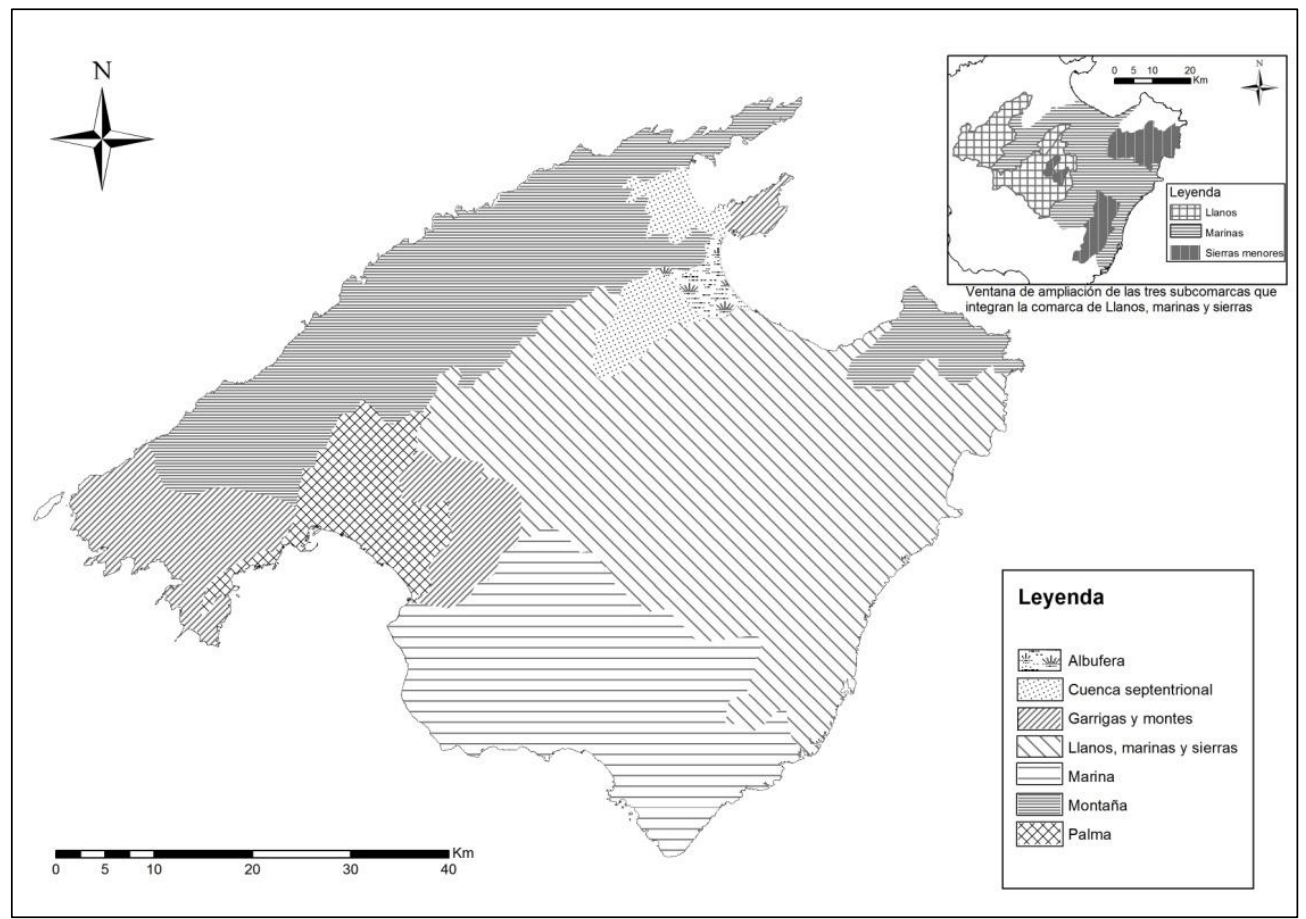

Figura 3. Mapa de comarcas cinegéticas de Mallorca

Fuente: Barceló, Grimalt y Binimelis, 2018.

Finalmente, cabe mencionar que el Departamento de Promoción Económica y Desarrollo Local del Consell de Mallorca colabora en el proyecto Scolopax Sin Fronteras dirigido por el Club de Cazadores de Becadas y que consiste en el seguimiento por radio-telemetría vía satélite de becadas en el Paleártico Occicental (http://rtvs.ccbp.org/).

Mediante el presente trabajo, se pretende realizar un estudio en detalle de la funcionalidad del visor de espacios cinegéticos del Consell de Mallorca durante el periodo 2013 - 2019, atendiendo a que se trata de una aportación novedosa en los campos de los sistemas de investigación geográfica y de la gestión de la actividad cinegética.

En este sentido, los objetivos específicos del presente artículo son:

I. Explicar cómo se ha llevado a cabo la integración de la información relativa a espacios cinegéticos y no cinegéticos de Mallorca en un sistema de información geográfica para disponer de una cartografía continua, detallada y en formato digital.

II. Evaluar las principales características de los visores de espacios cinegéticos del Consell de Mallorca y analizar la evolución del número de visitas, durante el periodo de análisis.

III. Valorar el uso y las repercusiones derivadas del visor de espacios cinegéticos.

IV. Definir los puntos fuertes en la planificación y la gestión cinegética asociados a la disponibilidad de tecnologías relacionadas con la información geográfica.

Se parte de la hipótesis que la digitalización de los terrenos de caza y su puesta a disposición pública mediante un visor en abierto y de acceso público tendrá una gran aceptación por parte del colectivo cinegético, sobretodo en cuanto a consultas de límites de terrenos libres, y al 
Barceló Adrover, A., Seguí Campaner, B., Guaita Mas, F. (2020): "Planificación y gestión de la caza en Mallorca. El visor de espacios cinegéticos del Consell de Mallorca”, GeoFocus, $n^{\circ} 25$, p. 121-151. http://dx.doi.org/10.21138/GF.660

mismo tiempo contribuirá a la mejora de la planificación y gestión territorial cinegética. Se prevé que la evolución de los datos anuales de visitas permita clasificar una o varias etapas del ciclo de vida del producto, lo cual, una vez definidas, supondrá una importante fuente de información para la toma de decisiones en cuanto a la funcionalidad futura de la herramienta web.

\section{Materiales, datos y métodos}

El objeto de análisis es la funcionalidad y resultados de uso del visor de espacios cinegéticos del Consell de Mallorca, en sus versiones de ordenador de sobremesa y dispositivos móviles.

\subsection{El caso de estudio.}

El Consell de Mallorca dispone de un Sistema de Información Territorial (SIT) corporativo donde se localiza la información geográfica de los diferentes departamentos que componen la institución. El SIT corporativo es un conjunto de procedimientos dirigidos a gestionar datos, orientado a promover los flujos de geoinformación dentro del Consell de Mallorca, y se compone de bases de datos, bases de conocimiento (procedimientos de análisis y gestión de datos) y de un sistema de interacción con el usuario.

Un aspecto muy importante del SIT, atendiendo a la realidad cambiante de la situación territorial, es que debe ser permanentemente actualizado. Por ello, el diseño dispone de mecanismos para su mantenimiento se gestiona mediante una unidad de coordinación y administración compuesto por especialistas en Tecnologías de la Información, Geografía y Cartografía, entre otros, que se coordinan con los responsables departamentales.

Con el traspaso de competencias en materia de caza desde el Gobierno de las Islas Baleares al Consell de Mallorca en 2010, y a raíz de la importancia que tiene la información geográfica relativa a terrenos cinegéticos, en 2012 se puso en marcha un proyecto para incorporar la información territorial cinegética dentro del Sistema de Información Territorial Corporativo del Consell de Mallorca con los objetivos de:

- Estructurar la información cartográfica digital del Servei de Caça para facilitar su uso interno y externo.

- Migrar la información territorial del Servei de Caça en la Base de Datos Corporativa (BDC).

A partir de aquí, se realizó una evaluación de la información disponible y de su estructura, y a continuación se propusieron las mejoras a realizar para que la información se pueda tratar de una forma ágil y eficiente. A continuación, se exponen las principales acciones realizadas:

1. Las capas en formato vectorial denominadas cotos de caza (incluye cotos de sociedades locales, cotos particulares, cotos sociales, cotos públicos y cotos intensivos), caza controlada (son zonas de caza controlada) y uniones de cotos de caza mayor (son cotos de caza mayor que se juntan) se unifican en una única capa denominada terrenos cinegéticos 
Barceló Adrover, A., Seguí Campaner, B., Guaita Mas, F. (2020): "Planificación y gestión de la caza en Mallorca. El visor de espacios cinegéticos del Consell de Mallorca”, GeoFocus, $n^{\circ} 25$, p. 121-151. http://dx.doi.org/10.21138/GF.660

con una tabla de atributos homogénea y con los mismos campos (matrícula, nombre, titular, fecha, editor, validación, etc.)

2. Las capas en formato vectorial denominadas campos de adiestramiento (espacios para el adiestramiento de perros de caza), reservas de caza (espacios incluidos en los cotos dónde no se puede cazar al objeto de promover el refugio y/o la reproducción de especies) y siembras (parcelas de siembras para la fauna) se unifican en una única capa denominada zonificación interna con una tabla de atributos homogénea y con los mismos campos (matrícula, nombre, titular, fecha, editor, validación, etc.)

3. La capa en formato vectorial denominada refugios de fauna (espacios excluidos de la actividad cinegética por motivos biológicos, científicos o educativos), junto con las zonas excluida de la actividad cinegética se unifican en una única capa denominada terrenos no cinegéticos con una tabla de atributos homogénea y con los mismos campos (matrícula, nombre, titular, fecha, editor, validación, etc.)

La información generada desde el Servei de Caça se estructura en tres complejas capas en el SIT corporativo. El personal técnico del Servei de Caça tiene acceso a toda la información con privilegios de edición, mientras que el resto de usuarios sólo podrán realizar consultas básicas de visualización y de acceso a datos no protegidos. Un aspecto a resaltar es la incorporación, en todas las capas, de un campo en formato fecha para la gestión histórica de las diferentes figuras cinegéticas y no cinegéticas.

Esta estructura SIT, aplicada a caza y a otras atribuciones de la institución, permite al Consell de Mallorca disponer de diferentes visores de mapas con el objetivo que la ciudadanía pueda consultar la información temática y de carácter público que produce la institución. Los visores disponibles son los siguientes:

- Visores genéricos

○ Visor IDE Mallorca

- Visor SIT Mallorca (uso interno)

- Visores temáticos

- Visor del Plan Territorial de Mallorca

- Visor de incidencias de carreteras

- Visor de las rutas de senderismo

- Visor de patrimonio histórico / Mapa de localización de bienes protegidos

- Visor de los espacios cinegéticos / Mapa de localización de cotos de caza

- Visor del diagnóstico de accesibilidad

- Visor de la Sierra de Tramuntana Paisaje Cultural

- Visores de mapas para dispositivos móviles

- Visor de incidencias de carreteras

- Visor de los espacios cinegéticos de Mallorca

En el caso que nos ocupa, el visor cartográfico de espacios cinegéticos del Consell de Mallorca (Figura 4) permite acceder a información geográfica sobre la actividad cinegética, aunque también presenta información territorial básica como son, entre otras, las unidades administrativas, los municipios, las entidades de población, las vías de comunicación o las imágenes satélite y ortofotos, Sus principales características son: 
Barceló Adrover, A., Seguí Campaner, B., Guaita Mas, F. (2020): "Planificación y gestión de la caza en Mallorca. El visor de espacios cinegéticos del Consell de Mallorca", GeoFocus, $n^{\circ}$ 25, p. 121-151. http://dx.doi.org/10.21138/GF.660

- Presenta una capa con los polígonos de espacios cinegéticos (cotos de caza) y no cinegéticos (refugios de fauna) de Mallorca. Los diferentes cotos se diferencian mediante una amplia variedad cromática.

- Proporciona información cartográfica de referencia: mapa topográfico, mapa de divisiones administrativas, catastro y ortofotografías de alta resolución y actualizadas.

- Permite la superposición y consulta de información cartográfica organizada en varias capas digitales.

- Dispone de herramientas que permiten consultar diferentes atributos asociados a cada coto / refugio de fauna, navegación, identificación y localización de elementos cartográficos.

- Permite aplicar transparencia a las diferentes capas del mapa.

- Alcanza un amplio rango de escalas de visualización, presentando la información entre las escalas 1: 360.000 y 1.500 aproximadamente.

- Permite realizar consultas geográficas tales como la búsqueda de un coto concreto, la localización de unas coordenadas o la ubicación de una parcela catastral por polígono y parcela o por referencia catastral.

- Permite añadir elementos gráficos (puntos, líneas, polígonos, textos) y realizar toma de medidas (longitud y áreas).

- Incorpora opciones para la impresión de mapas.

- Ofrece información precisa sobre cualquier punto de la capa de cotos y refugios de fauna: matrícula o número, coordenadas x, y (UTM y geográficas).

- Dispone de los contactos de las personas responsables del Consell de Mallorca responsables de la gestión del visor y permite desplegar información sobre la normativa cinegética insular.

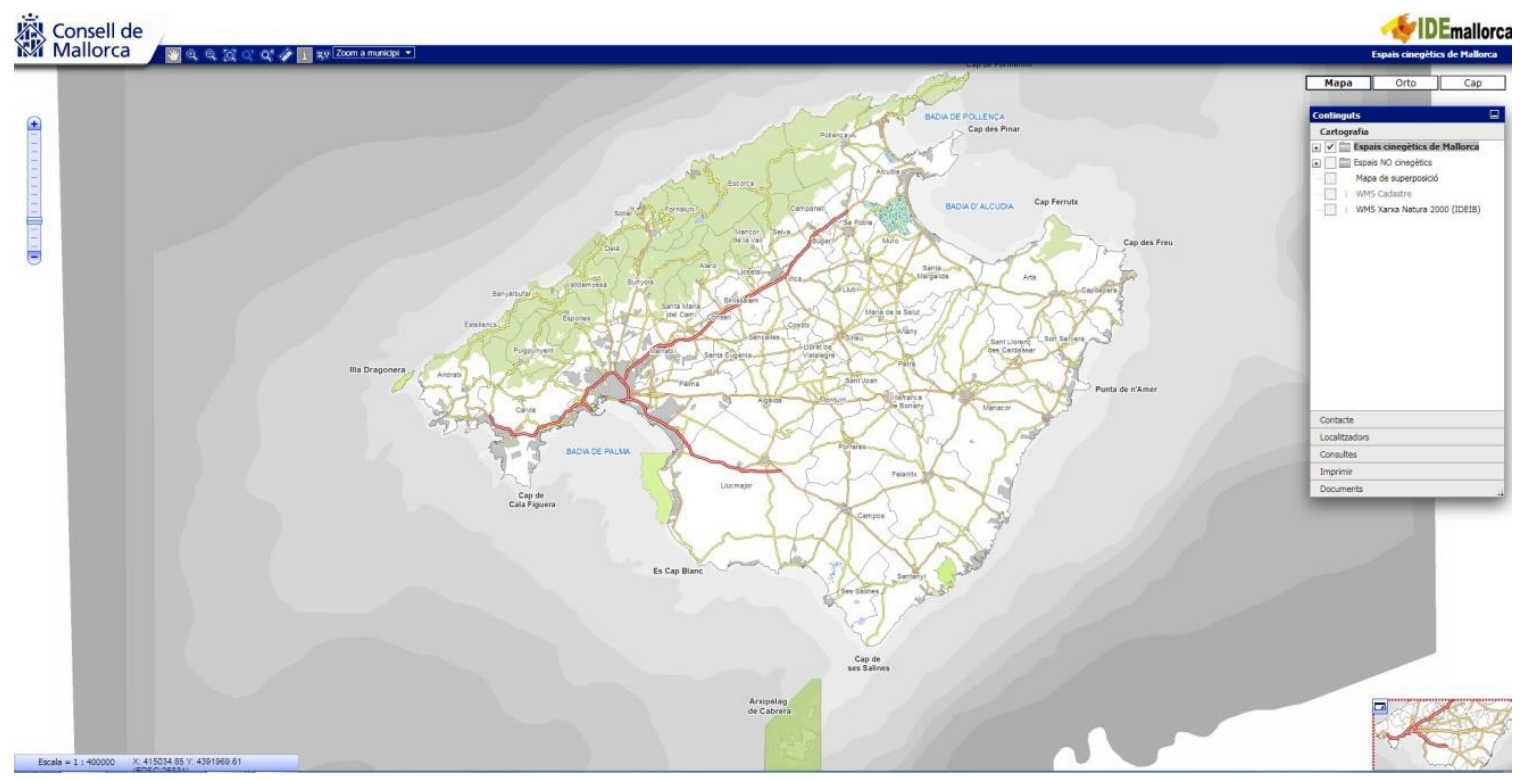

Figura 4. Captura de pantalla del visor de espacios cinegéticos del Consell de Mallorca. Fuente: http://www.conselldemallorca.info/sitmun/espais_cinegetics.jsp 
Barceló Adrover, A., Seguí Campaner, B., Guaita Mas, F. (2020): “Planificación y gestión de la caza en Mallorca. El visor de espacios cinegéticos del Consell de Mallorca", GeoFocus, $n^{\circ}$ 25, p. 121-151. http://dx.doi.org/10.21138/GF.660

El visor está integrado en la plataforma SITMUN (Sistema de Información Territorial Municipal), la cual permite la creación y gestión de aplicaciones web personalizadas en el ámbito de los sistemas de información geográfica. Está orientada a satisfacer las necesidades en materia de sistemas de información geográfica en el ámbito local y supramunicipal (Codinachs et al., 2013).

\subsubsection{Delimitación espacial.}

El presente estudio se enmarca en el ámbito territorial de Mallorca $\left(3.626 \mathrm{~km}^{2}\right)$, isla mayor del archipiélago balear, situada en la cuenca mediterránea occidental. Tiene forma romboidal con los ejes orientados en el sentido de los meridianos y paralelos, con unas distancias máximas de $96 \mathrm{~km}$ de este a oeste y de $76 \mathrm{~km}$ de norte a sur.

Mallorca cuenta con 53 municipios y una población de 880.113 habitantes (Ibestat, 2018). Las mayores densidades de población se encuentran en Palma, la capital, y en sus demarcaciones próximas. La estructura económica está marcada por la gran dimensión del sector terciario derivado del turismo y de los servicios asociados y por un moderada y baja representación de los sectores secundario y primario, respectivamente. A partir de mediados del siglo xx el desarrollo turístico ha conllevado aspectos tales como la construcción en espacios litorales, la habilitación de infraestructuras de apoyo, procesos continuos de éxodo rural y concentración poblacional en entornos urbanos, el incremento demográfico debido a la inmigración peninsular de mano de obra y el abandono progresivo de las actividades agroforestales lo cual en definitiva, supone una transformación cultural y paisajística particular asociada al modelo turístico. Actualmente, destaca el auge del fenómeno rururbano y el planteamiento de propuestas turísticas de calidad frente a las convencionales de sol y playa.

Físicamente, la isla presenta una combinación de espacios montañosos con zonas más llanas. Topográficamente, la Sierra de Tramuntana es el elemento de relieve más característico y se extiende paralelamente a la costa septentrional con alturas máximas superiores a $1.000 \mathrm{~m}$, destacando el puig Major $(1.445 \mathrm{~m})$ y el puig de Massanella $(1.365 \mathrm{~m})$, ambos en el municipio de Escorca. Paralelamente y en el extremo opuesto, se extienden las Sierras de Levante. Se trata de un conjunto de menor altitud y dimensiones, dónde sobresalen la Talaia Freda de Son Morei de Artà $(560 \mathrm{~m})$ y Sant Salvador de Felanitx $(510 \mathrm{~m})$. Entre los espacios montañosos se encuentran áreas más llanas o ligeramente onduladas con algunas elevaciones notables como Randa $(543 \mathrm{~m})$ en Algaida, el puig de Galdent (419 m) entre Algaida y Llucmajor o Bonany (315 m) en Petra. El clima insular es mediterráneo y se caracteriza por temperaturas moderadas, por un máximo pluviométrico en el otoño y precipitaciones escasas durante la época cálida. La red hidrográfica está formada por torrentes. La flora y la fauna son típicamente mediterráneas, aunque con diferencias respeto de la Europa septentrional a causa de aspectos climáticos, geológicos e históricos, destacando la presencia de valiosos endemismos. Entorno al $23 \%$ de la superficie insular está incluida en figuras relativas a espacios naturales protegidos o Red Natura 2000. Así mismo, desde el 2011, la Sierra de Tramuntana está declarada por la UNESCO Patrimonio de la Humanidad en la categoría de Paisaje Cultural.

En conjunto, Mallorca presenta una situación particular dentro del Mediterráneo, con características ambientales modificadas por intensa humanización en sucesivas etapas. Aun así, la actividad cinegética persiste muy activa, tanto en términos sociales como territoriales. 
Barceló Adrover, A., Seguí Campaner, B., Guaita Mas, F. (2020): "Planificación y gestión de la caza en Mallorca. El visor de espacios cinegéticos del Consell de Mallorca”, GeoFocus, $n^{\circ} 25$, p. 121-151. http://dx.doi.org/10.21138/GF.660

\subsubsection{Delimitación temporal.}

El período de análisis de datos de acceso a los visores de espacios cinegéticos del Consell de Mallorca es de 6 años, concretamente desde el mes de julio de 2013 (coincidiendo con la puesta en marcha del visor) al mes de junio de 2019.

\subsection{Los datos.}

Los datos manejados para evaluar y analizar las visitas a los visores de espacios cinegéticos del Consell de Mallorca se han obtenido mediante el informe Estadístiques d'accés als visors d'Espais Cinegètics emitido mensualmente por parte de Google Analytics, y que la IDE Mallorca remite el 1er día de cada mes al Servei de Caça del Consell de Mallorca. Google Analytics es una herramienta de análisis de tráfico de datos web que, a partir de filtros avanzados, emite un informe mensual el cual contiene, entre otros, el número de visitas a las páginas web del visor de sobremesa, visor móvil e impresiones realizadas. Igualmente, también ofrece un gráfico que representa el total de accesos a diario.

\subsection{Técnicas de análisis.}

Los datos obtenidos mensualmente se han tabulado sistemáticamente en diferentes tablas al objeto de poder realizar recuentos y elaborar los gráficos preceptivos. Por una parte, se ha elaborado una tabla mensual con el número de visitas a cada visor (de sobremesa y móvil), el número de impresiones y el total de accesos (visor de sobremesa, dispositivo móvil e impresiones). Esta información también se ha resumido en una tabla general que contiene el total de accesos por temporadas de caza. La información precedente también se representa con gráficos de barras y lineales con la intención de observar la evolución temporal de las visitas parciales a cada visor y el total de accesos. Ya en el apartado de discusión se presentan diferentes modelos cartográficos elaborados mediante la aplicación de herramientas SIG de geoprocesamiento (ArcGis de ArcMAP v. 10.5.1).

\section{Descripción y análisis de resultados.}

Se presentan las series diacrónicas de visitas a los visores de espacios cinegéticos y las impresiones realizadas (Tabla 3a y Tabla 3b), el total de visitas e impresiones por temporada de caza (Tabla 4), las variaciones porcentuales entre temporadas de caza (Tabla 5), una gráfica de barras de accesos anuales junto con una línea evolutiva de accesos y una línea de tendencia (Figura 5) por temporada de caza y una gráfica ejemplo de accesos diarios (Figura 6). Se entiende por temporada de caza el periodo comprendido entre el mes de julio de un año en concreto (coincidiendo en gran medida del inicio de la temporada de caza menor) hasta el mes de junio del año siguiente. 
Barceló Adrover, A., Seguí Campaner, B., Guaita Mas, F. (2020): "Planificación y gestión de la caza en Mallorca. El visor de espacios cinegéticos del Consell de Mallorca”, GeoFocus, $n^{\circ}$ 25, p. 121-151. http://dx.doi.org/10.21138/GF.660

Tabla 3a. Visitas a los visores de espacios cinegéticos e impresiones de mapas realizadas entre julio de 2013 y diciembre de 2016. Web: visor convencional. Imp.: Impresiones. Dm: visor para dispositivos móviles

\begin{tabular}{|c|c|c|c|c|c|c|c|c|c|c|c|c|}
\hline & \multicolumn{3}{|c|}{2013} & \multicolumn{2}{|r|}{2014} & & \multicolumn{2}{|r|}{2015} & & \multicolumn{2}{|r|}{2016} & \\
\hline Mes & Web & Imp & Dm & Web & $\operatorname{Imp}$ & Dm & Web & Imp & Dm & Web & Imp & Dm \\
\hline I & & & & 657 & 52 & 458 & 534 & 38 & 1130 & 724 & 37 & 1467 \\
\hline II & & & & 389 & 13 & 2 & 431 & 28 & & 526 & 17 & 1005 \\
\hline III & & & & 297 & 14 & 269 & 426 & 28 & & 41 & 20 & 58 \\
\hline IV & & & & 234 & 18 & 144 & 280 & 32 & 365 & 333 & 55 & 734 \\
\hline $\mathrm{V}$ & & & & 420 & 67 & 157 & 289 & 39 & 608 & 364 & 35 & 902 \\
\hline VI & & & & 746 & 84 & & 598 & 64 & 5 & 595 & 65 & 989 \\
\hline VII & 4 & 100 & $S$ & 663 & 43 & 267 & 686 & 36 & 852 & 703 & 20 & 1574 \\
\hline VIII & 205 & 86 & & 1096 & 91 & 492 & 1216 & 92 & 1902 & 1171 & 14 & 2311 \\
\hline IX & & & & 1001 & 64 & 600 & 879 & 41 & 1576 & 577 & 82 & 1511 \\
\hline $\mathrm{X}$ & 23 & 111 & 440 & 1305 & 132 & 741 & 1098 & 68 & 2016 & 868 & 46 & 1874 \\
\hline XI & 1124 & 74 & 56 & 1196 & 100 & 1366 & 1225 & 35 & 1665 & 784 & 34 & 2318 \\
\hline XII & 153 & 33 & 401 & 650 & 71 & 1027 & 838 & 45 & 1632 & 501 & 41 & 1681 \\
\hline Total & 6157 & 508 & 1405 & 8654 & 749 & 6056 & 8500 & 546 & 13378 & 7587 & 466 & 17224 \\
\hline
\end{tabular}

Fuente: elaboración propia a partir de datos de Google analytics - IDEmallorca.

Tabla 3b. Visitas a los visores de espacios cinegéticos e impresiones de mapas realizadas entre enero de 2017 y junio de 2019. Web: visor convencional. Imp.: Impresiones. Dm: visor para dispositivos móviles

\begin{tabular}{|l|r|r|r|r|r|r|r|r|r|}
\hline & \multicolumn{2}{|c|}{$\mathbf{2 0 1 7}$} & & \multicolumn{3}{|c|}{$\mathbf{2 0 1 8}$} & & $\mathbf{2 0 1 9}$ & \\
\hline Mes & Web & Imp & Dm & Web & Imp & Dm & Web & Imp & Dm \\
\hline I & 362 & 16 & 1520 & 286 & 23 & 1308 & 303 & 18 & 295 \\
\hline II & 354 & 55 & 916 & 202 & 18 & 816 & 257 & 19 & 118 \\
\hline III & 342 & 43 & 834 & 208 & 14 & 742 & 230 & 35 & 80 \\
\hline IV & 315 & 57 & 603 & 163 & 57 & 595 & 220 & 48 & 294 \\
\hline V & 285 & 28 & 589 & 178 & 26 & 657 & 226 & 31 & 131 \\
\hline VI & 363 & 28 & 820 & 290 & 16 & 1179 & 319 & 18 & 195 \\
\hline VII & 497 & 65 & 1222 & 320 & 23 & 927 & & & \\
\hline VIII & 574 & 42 & 2271 & 574 & 42 & 2271 & & & \\
\hline IX & 411 & 23 & 1381 & 411 & 23 & 1381 & & & \\
\hline X & 469 & 60 & 2469 & 469 & 60 & 2469 & & & \\
\hline XI & 333 & 48 & 2363 & 333 & 48 & 2363 & & & \\
\hline XII & 326 & 3 & 1852 & 326 & 3 & 1852 & & & \\
\hline Total & $\mathbf{4 6 3 1}$ & $\mathbf{4 6 8}$ & $\mathbf{1 6 8 4 0}$ & $\mathbf{3 7 6 0}$ & $\mathbf{3 5 3}$ & $\mathbf{1 6 5 6 0}$ & $\mathbf{1 5 5 5}$ & $\mathbf{1 6 9}$ & $\mathbf{1 1 1 3}$ \\
\hline
\end{tabular}

Fuente: elaboración propia a partir de datos de Google analytics - Idemallorca. 
Barceló Adrover, A., Seguí Campaner, B., Guaita Mas, F. (2020): "Planificación y gestión de la caza en Mallorca. El visor de espacios cinegéticos del Consell de Mallorca", GeoFocus, $n^{\circ}$ 25, p. 121-151. http://dx.doi.org/10.21138/GF.660

Tabla 4. Visitas a los visores de espacios cinegéticos e impresiones de mapas por temporada de caza, comprendida de julio a junio. Web: visor convencional. Imp.: Impresiones. Dm: visor para dispositivos móviles

\begin{tabular}{|c|r|r|r|r|}
\hline Temporada & \multicolumn{1}{|c|}{ Web } & \multicolumn{1}{c|}{ Imp. } & \multicolumn{1}{c|}{ Dm } & \multicolumn{1}{c|}{ Total } \\
\hline $2013-14$ & 8.900 & 756 & 2.968 & 12.624 \\
\hline $2014-15$ & 8.469 & 730 & 8.228 & 17.427 \\
\hline $2015-16$ & 8.925 & 546 & 15.598 & 25.069 \\
\hline $2016-17$ & 6.625 & 464 & 16.551 & 23.640 \\
\hline $2017-18$ & 3.937 & 395 & 16.855 & 21.187 \\
\hline $2018-19$ & 3.775 & 321 & 6.391 & 10.487 \\
\hline Total & 40.631 & 3.212 & 66.591 & 110.434 \\
\hline
\end{tabular}

Fuente: elaboración propia a partir de datos de Google analytics - Idemallorca.

Tabla 5. Evolución entre temporadas de las visitas a los visores de espacios cinegéticos e impresiones de mapas por temporada de caza, comprendida de julio a junio. Web: visor convencional. Imp.: Impresiones. Dm: visor para dispositivos móviles

\begin{tabular}{|l|r|r|r|r|}
\hline Temporada & Web & \multicolumn{1}{l|}{ Imp. } & \multicolumn{1}{l|}{ Dm } & \multicolumn{1}{l|}{ Total } \\
\hline $2014-15$ & $-4,84$ & $-3,44$ & 177,22 & 38,05 \\
\hline $2015-16$ & 5,38 & $-25,21$ & 89,57 & 43,85 \\
\hline $2016-17$ & $-25,77$ & $-15,02$ & 6,11 & $-5,70$ \\
\hline $2017-18$ & $-40,57$ & $-14,87$ & 1,84 & $-10,38$ \\
\hline $2018-19$ & $-4,11$ & $-18,73$ & $-62,08$ & $-50,50$ \\
\hline
\end{tabular}

Fuente: elaboración propia a partir de datos de Google analytics - IDEmallorca.

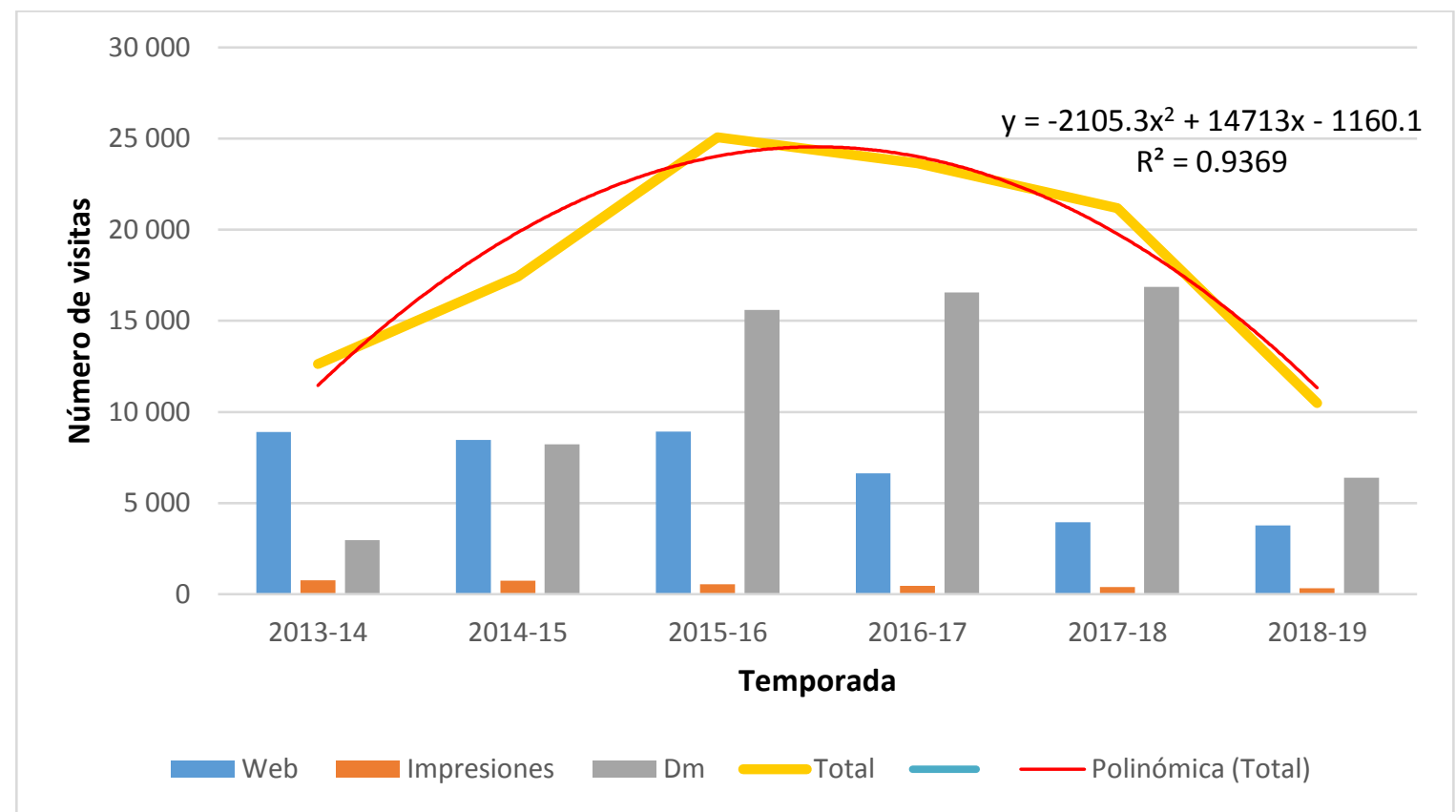

Figura 5. Evolución total y por tipología de dispositivo del número de visitas por temporada. Representación de la línea de tendencia.

Fuente: elaboración propia a partir de datos de Google analytics - Idemallorca. 
Barceló Adrover, A., Seguí Campaner, B., Guaita Mas, F. (2020): "Planificación y gestión de la caza en Mallorca. El visor de espacios cinegéticos del Consell de Mallorca”, GeoFocus, $n^{\circ}$ 25, p. 121-151. http://dx.doi.org/10.21138/GF.660

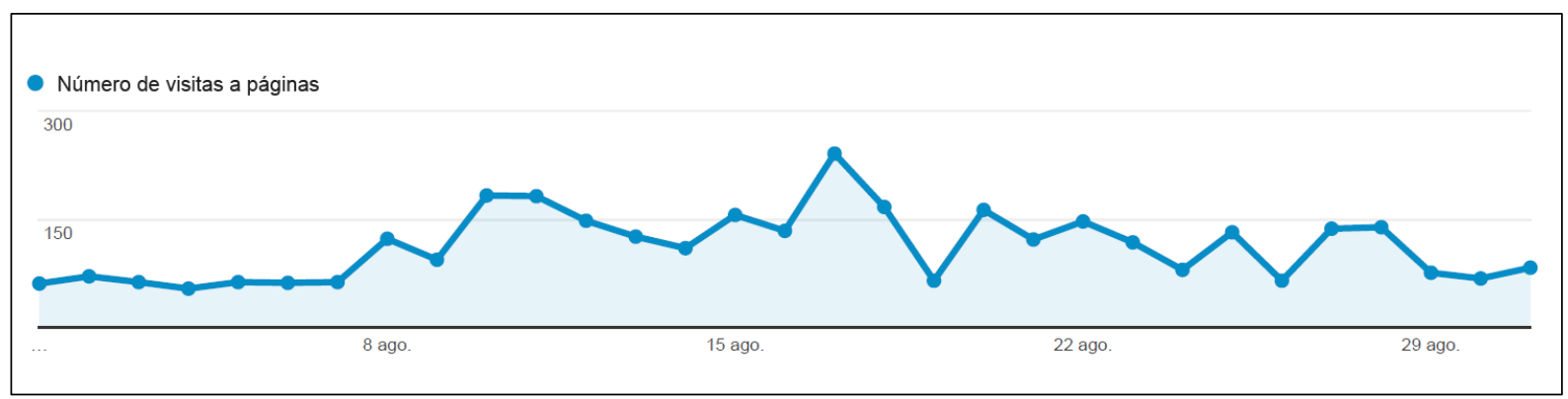

Figura 6. Visitas totales el mes de agosto de 2016

Fuente: Google analytics - IDEmallorca.

\section{Discusión y valoración de hallazgos}

La cartografía digital de terrenos cinegéticos que figura en los visores de la infraestructura de datos espaciales de Mallorca y en la página web del Servei de Caça, y que actualiza el Departamento de Promoción Económica y Desarrollo Local del Consell de Mallorca, es la que prevalece, con carácter general, a partir de la fecha de cada actualización.

La normativa con relación a la señalización y delimitación de los terrenos cinegéticos ha evolucionado claramente hacia una mayor definición territorial de los espacios cazables y no cazables mediante la intervención de las nuevas tecnologías sin dejar de lado las clásicas señales, aunque reduciendo su uso.

La puesta en escena de los visores de espacios cinegéticos resulta de especial interés por diferentes cuestiones:

1. Por su interés territorial, al ser la caza una activad que en Mallorca ocupa más del $75 \%$ de la superficie insular.

2. Por su accesibilidad, ya que se puede acceder a los visores desde diferentes plataformas.

3. Por su grado de precisión y fiabilidad, ya que los visores cinegéticos permiten concretar límites a pequeña escala, obviando interpretaciones o cuestiones estructurales como la falta de placas, señalizaciones erróneas, elementos físicos o humanos.

4. Por su manejabilidad e interoperabilidad, debido a que son visores muy intuitivos y con herramientas conocidas.

5. Por su constante actualización, atendiendo a que la información cartográfica se actualiza mensualmente.

6. Por la rapidez y fiabilidad de los datos publicados.

7. Por la profesionalidad y conocimiento de la materia de las personas que gestionan los visores de los espacios cinegéticos

8. Implicación del personal político, técnico, administrativo y de vigilancia del Servei de Caça en dar a conocer, elaborar manuales y dar formación para el uso de los visores.

No obstante, cabe indicar que existen una serie de puntos débiles los cuales se definen a continuación: 
Barceló Adrover, A., Seguí Campaner, B., Guaita Mas, F. (2020): “Planificación y gestión de la caza en Mallorca. El visor de espacios cinegéticos del Consell de Mallorca", GeoFocus, $n^{\circ}$ 25, p. 121-151. http://dx.doi.org/10.21138/GF.660

1. La edad media de la persona cazadora en Mallorca es de 53,5 años en 2013, y el segmento de edad de más de 60 años de gente que caza supone el 36,63\% del total del colectivo (Barceló, Grimalt y Binimelis, 2018). En este sentido, hay que considerar que una parte de la población con afición venatoria puede tener problemas para acceder a la información digital, por lo cual es preciso mantener la señalización convencional e impartir actividades formativas en cuanto al uso de los visores cinegéticos.

2. Existen zonas, de montaña principalmente, dónde la cobertura no es suficiente para el uso preciso de la geolocalización para los visores móviles.

3. La inmediatez en la publicación de la información digital puede tener efectos no deseados en caso de no detectarse errores. En una ocasión, por error, el gestor del SIG en materia cinegética no codificó correctamente los datos de fechas de un coto objeto de modificación geométrica. Así pues, al momento el coto dejo de publicarse en el visor de espacios cinegéticos y el terreno aparecía como terreno libre, hecho que fue detectado por un importante número de cazadores, y hasta que el titular no se puso en contacto con el Servei de Caça no se reparó. En efecto, los cambios deben ser realizados, validados y revisados.

En 72 meses de seguimiento mensual de la actividad de los visores de espacios cinegéticos, es decir 6 años, se han producido un total de 110.434 visitas, de las cuales $40.631(36,79 \%)$ se corresponde con el visor para ordenadores de sobremesa, $66.591(60,30 \%)$ con los dispositivos móviles y $3.212(2,91 \%)$ con impresiones en papel.

La evolución de consultas ha sido dispar si se considera la plataforma utilizada. Las consultas a los visores de terrenos cinegéticos mediante ordenadores de mesa fueron preponderantes aproximadamente hasta después de un año y medio desde su puesta en funcionamiento y, desde entonces, la dominancia de los dispositivos móviles ha sido prácticamente absoluta. Incluso en algunos meses concretos (noviembre de 2017) los dispositivos móviles septuplicaron las visitas en comparación con los ordenadores convencionales. Por su parte, las impresiones se han mantenido constantes con valores bajos en comparación con los visores, siendo los valores medios mensuales inferiores a 50 .

Si se analizan las visitas considerando las temporadas de caza (de julio al mes de junio del año siguiente), el registro anual de visitas a los visores presenta unos máximos coincidentes con la temporada de caza menor (de junio a enero). Se observan importantes picos de visitas entre los meses de junio y octubre acordes con las aperturas de los periodos de caza de las principales especies cinegéticas de caza menor en Mallorca que son el conejo (apertura en torno al 24 de junio), la torcaz (media veda, apertura el 15 de agosto) y el tordo y la perdiz (caza menor en general, apertura el 12 de octubre). De hecho, el mes con el número máximo absoluto de visitas es agosto de 2016 con un total de 3.496. En la gráfica correspondiente (véase Figura 6) se puede observar como el día con mayor número de visitas coincide con la víspera (miércoles, 17 de agosto) de la primera jornada en que se permite la caza en la media veda en los terrenos libres.

La evolución interanual absoluta entre temporadas cinegéticas es positiva entre 2013-2014 y 2015-16. Además del contenido innovador de los visores, cabe tener en cuenta el esfuerzo realizado por el Servei de Caça del Consell de Mallorca en dar a conocer las diferentes aplicaciones tanto en los medios de comunicación como en actividades formativas dirigidas a colectivos estratégicos (directivas de asociaciones de cazadores, personal de vigilancia, etc.) o elaborando tutoriales básicos de uso y de distribución general a personas interesadas. A partir de 2016 -17, las temporadas presentan ya valores de decrecimiento. Particularizando el estudio por medios de 
Barceló Adrover, A., Seguí Campaner, B., Guaita Mas, F. (2020): "Planificación y gestión de la caza en Mallorca. El visor de espacios cinegéticos del Consell de Mallorca", GeoFocus, $n^{\circ}$ 25, p. 121-151. http://dx.doi.org/10.21138/GF.660

consulta, los ordenadores de sobremesa y las impresiones ofrecen, prácticamente desde el inicio, importantes descensos entre años, proceso más acusado en los ordenadores que en las impresiones. Por su parte, los dispositivos móviles muestran cifras de consultas crecientes entre 2013-14 y 201718 , si bien en la última temporada muestra una fuerte recesión.

En su conjunto, el uso de los visores cinegéticos de Mallorca muestra un importante grado de consultas entre las temporadas 2013-14, 2014-15 y 2015-16, siendo en esta última temporada cuando obtiene su máximo de consultas (25.069 / 22,70\% del total del periodo estudiado), duplicando cifras de la primera temporada. Desde entonces, baja el número total de consultas y, ya para la temporada 2018-19, el decrecimiento es muy notable. La línea de tendencia estimada ilustrativa de un modelo de crecimiento, saturación y agotamiento (declinación inmediata, ver Figura 5) prácticamente simétrico, responde con un buen ajuste $\left(\mathrm{R}^{2}=0,936\right)$ a una función polinómica con las características descritas.

Las causas que mejor pueden explicar esta evolución y ajuste al modelo descrito, tienen relación, por una parte, con la mejor definición de límites de los terrenos cinegéticos, con el consecuente conocimiento y percepción territorial del colectivo cinegético, entre otros, por el trabajo del Servei de Caça del Consell de Mallorca y, por otra, con la disponibilidad de terrenos libres.

El hecho de que desde 2013 el Consell de Mallorca ponga a disposición de la ciudadanía de herramientas digitales intuitivas y específicas sobre terrenos cinegéticos y no cinegéticos, supuso un notable avance en la disposición de información territorial cinegética que hasta el momento debía de consultarse mediante expedientes físicos o con visitas de campo, y no siempre la realidad coincidía con los mapas administrativos. Esta situación supuso el inicio de un proceso de consultas y uso masivo de los visores por parte de personas propietarias, gestores de cotos, administraciones, profesionales del sector y, evidentemente, del colectivo cinegético. Consecuentemente, y teniendo en cuenta que legalmente la cartografía digital prevalecía sobre la señalización de campo, se detectaron muchas y diversas situaciones, en las cuales el Servei de Caça tuvo que actuar, tanto a instancia de parte como de oficio para corregir un gran número de discrepancias de límites. Cabe destacar que se realizaron numerosas salidas de campo con profesionales técnicos y de vigilancia del Servei de Caça acompañados por propietarios/as, titulares de cotos y cazadores en todas las comarcas de la isla, resolviéndose, con distinto grado de trabajo, todas y cada una de les peticiones efectuadas. De hecho, en diversas ocasiones la propiedad, gracias a la información geocinegética concretaron ya no sólo los límites de los cotos sino también los de propiedad, lo cual requirió de la preceptiva tramitación de expedientes de regularización con catastro, lo que supone una función de visualización por parte del visor de conflictos territoriales no cinegéticos.

Otro factor a considerar son los terrenos libres o de aprovechamiento común, y en los cuales cazan habitualmente un 22,28 \% de los cazadores (Barceló Adrover, Binimelis Sebastián y Grimalt Gelabert, 2016). Estos espacios aparecen concentrados alrededor de los principales núcleos de población, Palma, Inca y Manacor y en sus áreas de influencia transformadas por infraestructuras y actividades incompatibles con la caza, en el litoral urbanizado, en espacios montañosos y de difícil acceso y allí donde hay predominio de la propiedad pública. Es decir, afloran en entornos con aptitudes cinegéticas modestas, con limitaciones prácticas asociadas a fenómenos urbanos o dificultades físicas. Entre las temporadas de caza 2011-2012 y la 2018-2019 se observa una importante reducción de los ayuntamientos que autorizan la caza en los terrenos libres, pasando de 41 municipios acogidos al plan marco en la temporada 2011-2012 a 25 en la actualidad (Tabla 6). La presencia de cazadores foráneos en los terrenos libres, la existencia de conflictos entre cazadores 
Barceló Adrover, A., Seguí Campaner, B., Guaita Mas, F. (2020): "Planificación y gestión de la caza en Mallorca. El visor de espacios cinegéticos del Consell de Mallorca", GeoFocus, $n^{\circ}$ 25, p. 121-151. http://dx.doi.org/10.21138/GF.660

y propietarios, las modalidades practicadas o la intensidad del impacto acústico de la caza a puesto fijo sobre los nuevos usos residenciales y turísticos del campo mallorquín parece que son los principales factores que condicionan las decisiones consistoriales de habilitar o no la caza en los terrenos de régimen cinegético común. En Palma, la decisión de no habilitar la caza en los terrenos libres ha sido motivo de manifestaciones y reivindicaciones de los cazadores afectados, sobre todo aquellos que no disponen de un coto privado, no pertenecen a ninguna sociedad de cazadores o no tienen recursos. La progresiva inhabilitación cinegética de estos espacios puede suponer altas concentraciones en los libres dónde sí se puede cazar o el abandono de la práctica por falta de terrenos hábiles, entre otras circunstancias (Barceló Adrover, Grimalt Gelabert y Binimelis Sebastián, 2018). Deben recordarse también las repercusiones derivadas de altas concentraciones de especies como la torcaz en espacios libres y cotos de los entornos periurbanos.

Tabla 6. Municipios adheridos al plan marco del Consell de Mallorca

\begin{tabular}{|c|c|c|}
\hline Temporada & $\begin{array}{l}\text { Municipios adheridos } \\
\text { al plan marco }\end{array}$ & Porcentaje \\
\hline 2011-12 & 41 & 77,36 \\
\hline 2012-13 & 35 & 66,04 \\
\hline 2013-14 & 35 & 66,04 \\
\hline 2014-15 & 34 & 64,15 \\
\hline $2015-16$ & 31 & 58,49 \\
\hline $2016-17$ & 28 & 52,83 \\
\hline 2017-18 & 26 & 49,06 \\
\hline 2018-19 & 25 & 47,17 \\
\hline
\end{tabular}

Fuente. Elaboración propia sobre datos proporcionados por el Servei de Caça del Consell de Mallorca.

En términos generales, el análisis global del número de visitas que han recibido los visores cinegéticos del Consell de Mallorca desde su puesta a punto hasta la actualidad permite definir notables similitudes con el denominado ciclo de vida, concepto ampliamente utilizado en el marketing empresarial (Secco et al., 2016) o de productos (Barrios, 2017), entre muchos otros. En el ámbito turístico, el Modelo de los Ciclos de Vida de los Destinos Turísticos desarrollado por Richard Butler (Butler, 1980) en base a otros campos, con sus múltiples adaptaciones, interpretaciones y cuestionamientos, define las diferentes etapas evolutivas (Figura 7) aplicables a un destino turístico. El ciclo se inicia con una fase incipiente de exploración ligada a la implicación de diferentes agentes, lo cual propulsa la etapa de desarrollo. En la fase de consolidación, se alcanzan niveles record de demanda, disminuye el ritmo de crecimiento y termina por estancarse. Es a partir de esta etapa cuando se pueden suceder diferentes trayectorias, lo cual dependerá de la planificación, gestión e innovación que se aplique. 
Barceló Adrover, A., Seguí Campaner, B., Guaita Mas, F. (2020): "Planificación y gestión de la caza en Mallorca. El visor de espacios cinegéticos del Consell de Mallorca", GeoFocus, $n^{\circ}$ 25, p. 121-151. http://dx.doi.org/10.21138/GF.660

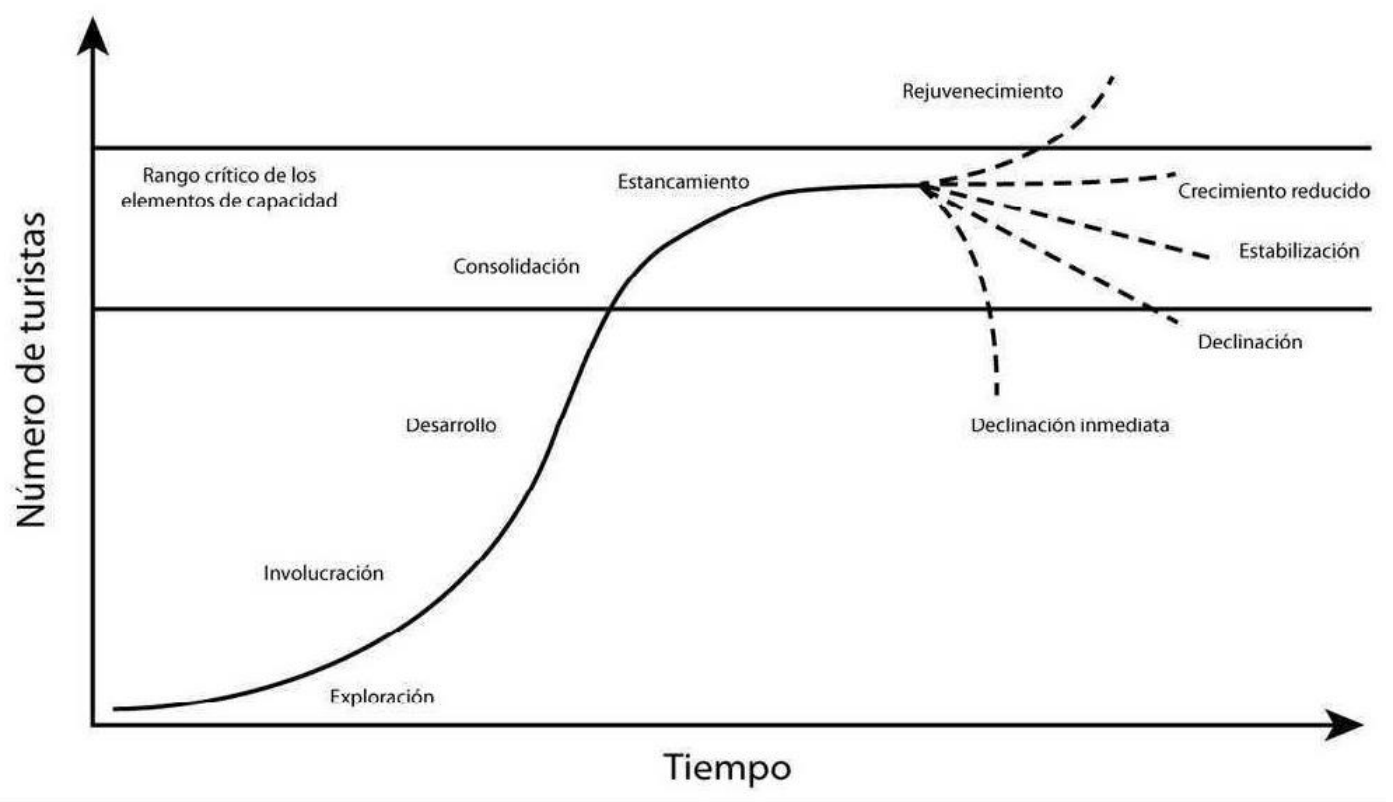

Figura 7: Representación del ciclo de evolución de un área turística.

Fuente: Portal Valenzuela, B. F. Espinoza Ramírez, J. C., y Carreño Zúñiga, M. (2014) a partir de Butler (1980).

La evolución del número de visitas total por temporada a los visores cinegéticos del Consell de Mallorca (Figura 5) presenta, como se ha indicado anteriormente, ciertos paralelismos con el modelo descrito por Butler. Este paralelismo se establece sobre el recurso constituido por el visor, y no sobre el uso cinegético como recurso. De hecho, desde la temporada 2015-2016, la cual marca un punto de inflexión pasando del crecimiento al estancamiento y posterior receso, se ha pasado en primer lugar por una fase de declinación (2016-2017) seguida por otra de declinación inmediata (2017-2018). Los principales factores a considerar son varios. Por una parte, el menor uso de las aplicaciones debido a la mejor percepción, conocimiento y señalización de los territorios de caza, lo cual permite que la personas que practican la actividad cinegética reduzcan el uso de la tecnología porque los límites están claros. Además, más del 90 \% del colectivo (Barceló, 2015) practica la caza en sólo uno o dos espacios cinegéticos, lo cual supone una alta fidelidad y consecuente alto conocimiento de las zonas de caza. Por otra parte, la progresiva disminución de municipios incorporados al plan marco de los terrenos de régimen cinegético común repercute en un menor uso de los visores. Y en el mismo sentido puede estar actuando la falta de recambio generacional entre los cazadores, lo que da lugar no ya a una población cerrada, sino decreciente. Un análisis exhaustivo y comparativo de los cambios relativos a los terrenos libres indica que entre las temporadas 2014 - 2015 y 2018-2019, el número de municipios acogidos al plan marco ha descendido un 16,98\% (se ha pasado de 34 a 25 municipios en los cuales se puede cazar en lo libre, aunque a nivel de superficie, y en base a datos de Barceló (2015) esta disminución se traduce en un descenso del 38,45\% de espacio libre practicable (se ha pasado de disponer de 43.822,18 ha a 26.974,62 ha aptas para la caza en terrenos de régimen común). Estos factores junto con la posible disminución de la calidad cinegética de los terrenos libres y su progresiva localización lejos de municipios con altos números de licencias de caza inciden que de cada vez haya menos terrenos por descubrir y más fidelización de los cazadores en los espacios aptos de los municipios acogidos al plan marco. En consecuencia, se intuye un menor uso de los aplicativos de espacios cinegéticos. 
Barceló Adrover, A., Seguí Campaner, B., Guaita Mas, F. (2020): "Planificación y gestión de la caza en Mallorca. El visor de espacios cinegéticos del Consell de Mallorca", GeoFocus, $n^{\circ}$ 25, p. 121-151. http://dx.doi.org/10.21138/GF.660

Atendiendo a la situación actual de progresiva recesión en el número de visitas a los visores de espacios cinegéticos se considera necesario la introducción de nuevas opciones prácticas y útiles en relación a la aplicación de medidas que contribuyan a la ordenación cinegética. En este sentido, se propone la introducción de innovaciones en el visor que permitan disponer de información territorial detallada (por ejemplo, obtener fichas con la información cinegética a nivel parcelaria siguiendo el modelo del Plan Territorial de Mallorca), incorporar capas dependientes de otras administraciones, posibilitar conexiones WMS / descargas de capas propias para facilitar su uso en sistemas de información geográfica (Chinchilla, 2015). De la misma manera, también se pueden crear nuevas capas con información aportada por el propio colectivo (por ejemplo, capa de riesgos geográficos) y facilitar el intercambio de información cinegética con interfaces de usuarios de otros colectivos con el fin de evitar conflictos.

Además de las propuestas anteriores, resultan estratégicas las funcionalidades que contribuyan a la mejora de la planificación y la gestión cinegética, aspectos fundamentales en la gestión de las especies de caza y los ecosistemas que habitan (Gálvez-Bravo y Cassinello, 2013). Por ello, los visores cinegéticos deben permitir obtener de forma fácil la información cartográfica que se solicita la hora de aprobar/renovar los planes técnicos de caza, deben facilitar la introducción y ubicación (coordenadas UTM) de símbolos de elementos de gestión como comederos, bebederos, jaulas trampa, siembras o estructuras de piedra en seco, entre otros (Figura 8), o llevar a cabo censos o recuentos de capturas. Estos elementos se presentan como relevantes, ante nuevos escenarios normativos y de gestión social y administrativo del recurso cinegético actual.

Otro supuesto en el cual podrían tomar partido los visores, atendiendo a la notable intensidad organizativa de actividades eventuales de tiro deportivo (tiro al plato, Compak Sporting ${ }^{\circledR}$, recorridos de caza o hélices en los meses de veda por parte de asociaciones cinegéticas o clubs de caza, seria en ofrecer opciones digitales para ubicar las líneas de tiro y calcular las medidas de seguridad requeridas para los campos de tiro según el Reglamento de Armas (Figura 9).

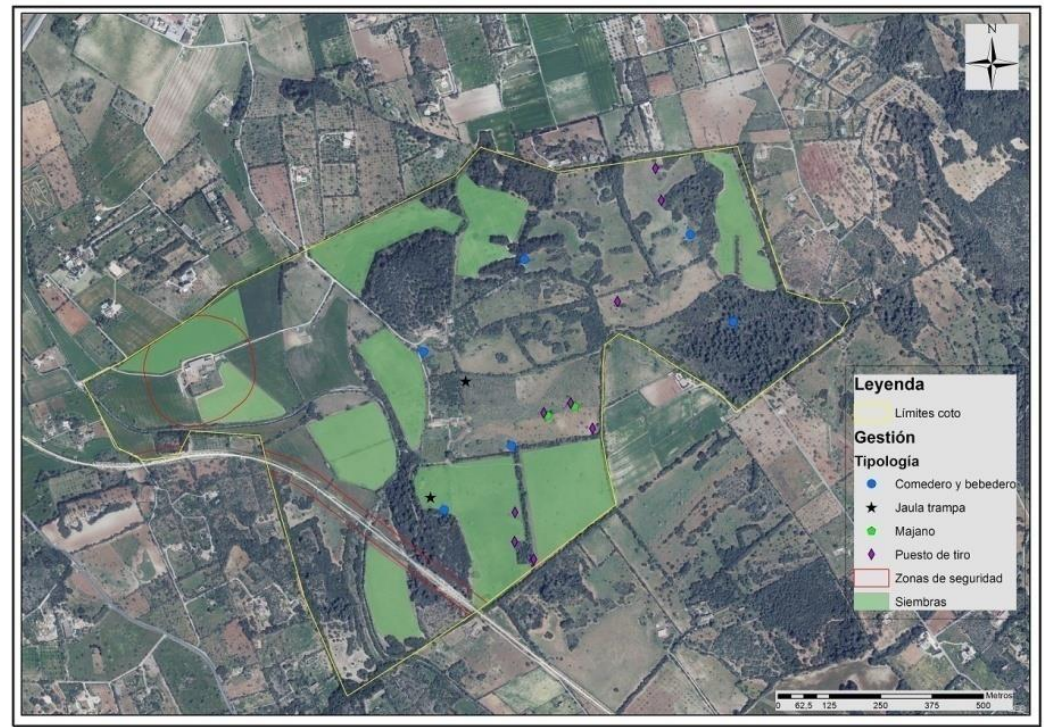

Figura 8: Zonificación de un coto de caza menor en Mallorca.

Fuente. Elaboración propia 
Barceló Adrover, A., Seguí Campaner, B., Guaita Mas, F. (2020): "Planificación y gestión de la caza en Mallorca. El visor de espacios cinegéticos del Consell de Mallorca", GeoFocus, $n^{\circ}$ 25, p. 121-151. http://dx.doi.org/10.21138/GF.660

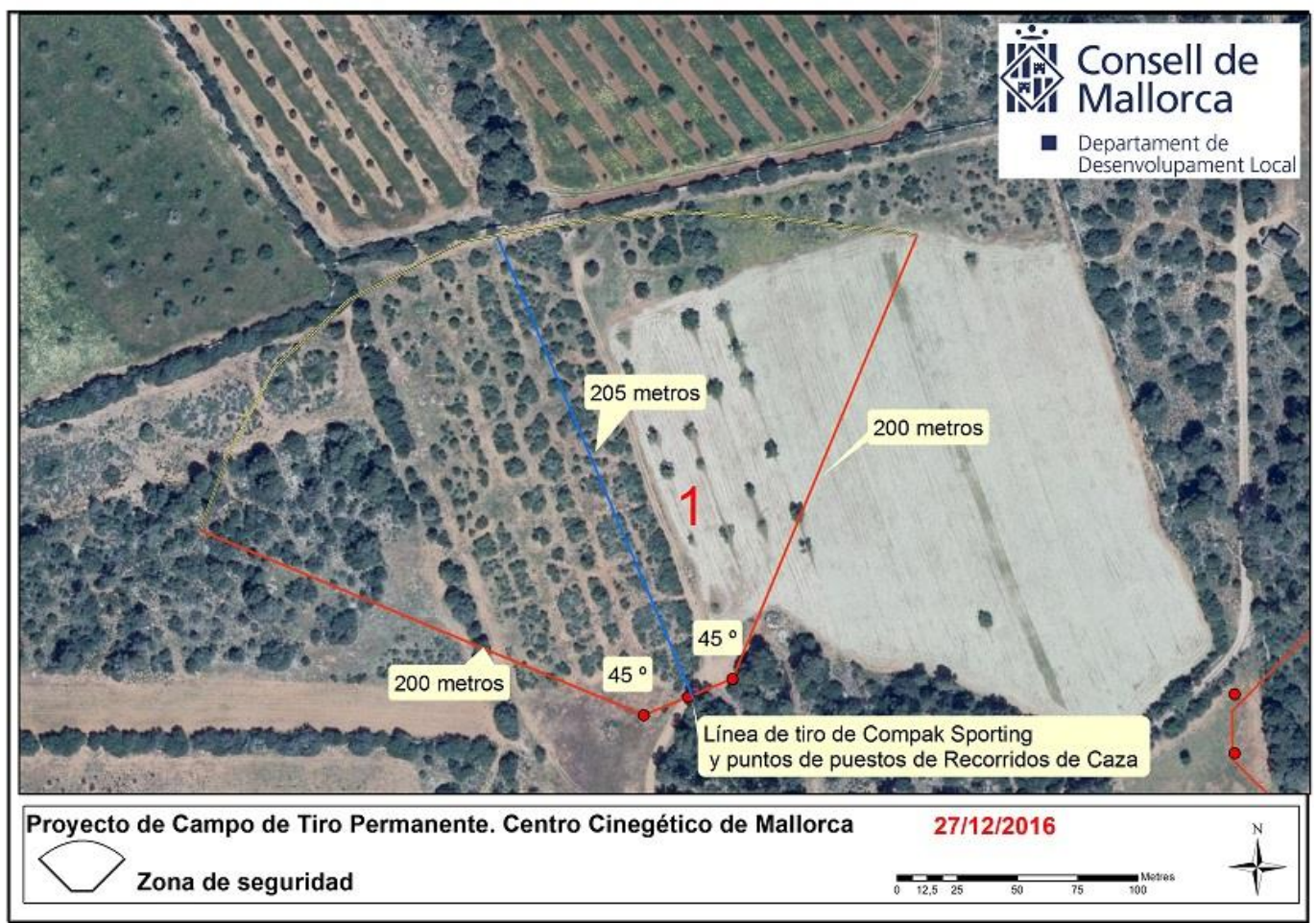

Figura 9: Radio de seguridad de un campo de tiro con sus ángulos y distancias reglamentarias.

Fuente: Servei de Caça del Consell de Mallorca.

En conjunto, el potencial de estas herramientas digitales supone una oportunidad para mejorar la calidad de los hábitats, de las especies cinegéticas y de la actividad en general, por lo cual puede ser muy recomendable diseñar procesos participativos en los cuales las asociaciones de cazadores y colectivos cinegéticos puedan aportar ideas o necesidades para que se estudie su implantación.

\section{Conclusiones}

La Infraestructura de Datos Espaciales del Consell de Mallorca (IDEmallorca) tiene como objetivo general integrar a través de Internet los datos, metadatos, servicios e información de tipo geográfico que se producen en el Consell de Mallorca, facilitando a la sociedad la localización, identificación, selección y acceso a estos recursos, a través de un geoportal. En base a estos antecedentes y al objeto de aumentar la transparencia informativa, de dar a conocer la información territorial disponible y de promover la accesibilidad pública, el 2013 el Consell de Mallorca habilitó un visor temático sobre los espacios cinegéticos, lo cual supuso una novedosa innovación tecnológica en el sector.

Sin duda alguna, la adaptación del visor a dispositivos móviles o portátiles dotó de aún más calidad y utilidad a estas herramientas que ofrecen información detallada de los límites de las diferentes 
Barceló Adrover, A., Seguí Campaner, B., Guaita Mas, F. (2020): “Planificación y gestión de la caza en Mallorca. El visor de espacios cinegéticos del Consell de Mallorca", GeoFocus, $n^{\circ}$ 25, p. 121-151. http://dx.doi.org/10.21138/GF.660

tipologías de terrenos cinegéticos y no cinegéticos. Hasta el momento toda esta información debía de obtenerse mediante la señalización de campo o consulta en múltiples mapas a diferentes escalas, disponibles en los archivos de las personas titulares de cotos de caza o en la administración.

La disposición pública de los visores cinegéticos, dotados de precisión métrica, ha permitido definir claramente los límites de los terrenos de caza al mismo tiempo que ha posibilitado el descubrimiento y accesos a espacios aptos para la caza, sobretodo en cuanto a terrenos libres se refiere y en un territorio ampliamente parcelado como es la isla de Mallorca, así como facilitar la evaluación y planificación de usos rurales (cinegéticos y no cinegéticos) desde el punto de vista de compatibilidad.

Los principales puntos fuertes de los visores cinegéticos son su accesibilidad, fiabilidad, facilidad de uso y gratuidad, con geodatos en constante actualización. La labor técnica de actualización de datos es de detalle, con revisiones y subsanaciones de errores constantes, debido a la inmediatez en la publicación de datos.

Un aspecto fundamental que ha contribuido al mayor uso de los visores, aunque su finalidad web sólo sea consultiva, es el amparo jurídico ya que la cartografía digital oficial de los terrenos cinegéticos prevalece a todos los efectos sobre la señalización de campo. Así mismo cabe considerar la contribución ambiental de los visores digitales debido a la reducción del uso de mapas en papel. Por otra parte, y como principal factor limitante, cabe tener en cuenta que un importante segmento del colectivo cinegético por razones de edad ha tenido dificultades para su interrelación activa con las nuevas tecnologías. En este caso, el Servei de Caça del Consell de Mallorca ha realizado una importante labor didáctica e informativa con las personas con menor potencial de acceso a estos servicios.

Analizados los datos globales de uso de los visores entre el 2013 y 2019 se observa que el ciclo de vida del producto tecnológico ha pasado ya por las etapas emergentes y en la actualidad se encuentra en decadencia, básicamente por agotamiento de sus utilidades iniciales.

Es ahora cuando deben plantearse nuevos retos para una herramienta tan potente, funcional y práctica como los visores cinegéticos. La introducción de nuevas opciones particulares debería ser una prioridad, lo cual podría ser contrastado fomentando la recogida de datos a partir de procesos participados de asociaciones, club, entidades, profesionales y del colectivo cinegético en general. Aunque, sin duda, un campo en el que las nuevas tecnologías deberían tener un amplio recorrido es en la planificación y gestión cinegética, desde el apoyo a la preparación de las jornadas de caza o a la disposición de información cartográfica para aportar en los planes técnicos hasta la posibilidad de diseñar propuestas prácticas de ordenación y mejoras de los acotados, analizar mediante datos censales de capturas y censos los estados poblaciones y promover la accesibilidad y el intercambio de información entre particulares y administración.

En esta línea de nuevas propuestas y al objeto de relanzar los visores temáticos, cabe destacar las oportunidades que ofrece el desarrollo de propuestas participativas relacionadas con la ciencia ciudadana en múltiples campos (Borsellino, 2017; Chic, 2019; García González, 2019; Walteros, 2019). Se trata de comprometer seriamente a los ciudadanos en sus problemas, aprovechando también sus aficiones y gustos para la aportación de datos y la contribución al avance y la difusión del conocimiento científico (Capel, 2010). En cualquier caso, se puede afirmar que el alto nivel organizativo del colectivo cinegético junto con su amplia distribución territorial, los conocimientos prácticos y sus finalidades ambientales, son algunos de los principales puntos fuertes que permiten impulsar iniciativas conducentes a una nueva cultura científica, más democrática y 
Barceló Adrover, A., Seguí Campaner, B., Guaita Mas, F. (2020): “Planificación y gestión de la caza en Mallorca. El visor de espacios cinegéticos del Consell de Mallorca", GeoFocus, $n^{\circ}$ 25, p. 121-151. http://dx.doi.org/10.21138/GF.660

dónde las personas practicantes de una actividad concreta aportan valiosos datos y puntos de vista a los proyectos de investigación. En el entorno cinegético insular, este método de trabajo ha sido recurrente en interesantes aportaciones (Santandreu et al., 2002; Ortega et al., 2002; Prohens y Seguí, 2013; Barceló, Binimelis y Grimalt, 2016; Pons et al., 2019). No obstante, la habilitación de herramientas tecnológicas, institucionales, de uso público, intuitivas, y de fácil acceso abre la puerta a nuevos horizontes de trabajo científico. En este sentido, el Servei de Caça del Consell de Mallorca utiliza datos aportados por personas voluntarias y colaboradoras en el seguimiento de especies (Muñoz et al., 2019 a y b; Rodríguez-Tejeiro et al., 2019) y en la planificación y gestión cinegética (Barceló, Grimalt y Binimelis, 2018). Por otra parte y en el ámbito nacional, cabe destacar el proyecto "Observatorio Cinegético" (www.observatoriocinegetico.org), promovido por Fundación Artemisan y Real Federación Española de Caza, que consiste en la monitorización de especies cinegéticas a través de los censos voluntarios de cazadores y gestores, los trabajos de investigación basados en encuestas al colectivo que permiten definir modelos de aprovechamiento cinegético (Martín, Rengifo y Sánchez, 2019) o el ya mencionado proyecto "Scolopax Sin Fronteras" del CCBP, entre otros.

El colectivo cinegético tal vez por la autocrítica a la que se ha visto sometido o por la criticas externas recibidas, ha experimentado una evolución que le supone nuevas potencialidades ante iniciativas como las que tratamos, suponiendo a día de hoy un eslabón fundamental entre lo rural y lo urbano que adolece en otros colectivos. Es aquí cuando la administración competente en materia de caza junto con los homólogos en nuevas tecnologías, tienen que analizar la situación y proporcionar a los visores las opciones necesarias para el desarrollo de tareas específicas que garanticen su mejora continua y permitan mostrar avances en la modernización de la administración. En efecto, gran parte de las necesidades planteadas fundamentan el desarrollo del proyecto SmartCaça por parte del Consell de Mallorca de forma paralela y complementaria al visor objeto de este estudio.

\section{Referencias bibliográficas}

Antich Adrover, F. y Salom Sancho, J. M. (2003). De terres de Marina a la parroquia de s'Horta. Pollença: Associació Cultural Es Majora, El Gall Editor. 398 pág

Amaro-Mellado, J.-L., y Antón, D. (2016). Spatial data infrastructure as a tool for cultural heritage management. In F. Felip Miralles, J. Gual Ortí, M. Cabeza González, \& C. García-García (Eds.), Drawing, Building, Dreaming. Research on graphic expression applied to building (1st ed., pp. 1025-1035). Valencia: Tirant Lo Blanch. Recuperado de http://www.tirant.com/editorial/libro/9788491434856\#

Barceló Adrover, A. y Grimalt Gelabert, M. (2014). La huella cinegética en Mallorca. Piedra en seco y gestión de la caza. En D. Pavón Gamero, A. Ribas Palom, S. Ricart Casadevall, A. Roca Torrent, I. Salamaña Serra y C. Tous de Sousa (Eds)., XVII Coloquio de Geografía Rural. Revalorizando el espacio rural: leer el pasado para ganar el futuro (pp. 745-758). Recuperado de https://parqueagrariofuenlabrada.es/wp-content/uploads/2014/09/XVII-Coloquio-de-Geografia$\underline{\text { Rural.pdf }}$

Barceló Adrover, A., Grimalt Gelabert, M. y Binimelis Sebastián, J. (2015). Implicaciones territoriales, sociales y ambientales de las sociedades de cazadores locales en Mallorca. En 
Barceló Adrover, A., Seguí Campaner, B., Guaita Mas, F. (2020): "Planificación y gestión de la caza en Mallorca. El visor de espacios cinegéticos del Consell de Mallorca”, GeoFocus, $n^{\circ} 25$, p. 121-151. http://dx.doi.org/10.21138/GF.660

J. de la Riva, P. Ibarra, R. Montorio, y M. Rodrigues, (Eds.), XXIV Congreso de la Asociación Española de Geógrafos. Análisis espacial y representación geográfica: innovación $y$ aplicación (pp 1543-1552). Recuperado de http:// congresoage.unizar.es/eBook/trabajos/163_Barcelo\%20Adrover.pdf

Barceló Adrover, A. y Seguí Campaner, B. (2017). Anàlisi dels aspectes socials de la caça a Mallorca: distribució territorial, anàlisi per edats i gèneres, tipologies de llicències i comparatives. Boll. Soc. Hist. Nat. Balears, 60, 65-89. Recuperado de https://www.raco.cat/index.php/BolletiSHNBalears/article/ view/338452

Barceló Adrover, A., Binimelis Sebastián, J. y Grimalt Gelabert, M. (2016). Caracterización del perfil social y territorial del cazador mallorquín. En A.R. Ruíz Pulpón, M.A. Serrano de la Cruz Santos- Olmo y J. Plaza Tabasco (Coords), Treinta años de Política Agraria Común en España (pp. 496-511). Recuperado de https://dialnet.unirioja.es/servlet/articulo?codigo=6274404

Barceló Adrover, A. (2015). Caça, territori i Societat a Mallorca. Tesis doctoral. Universitat de les Illes Balears, 638 pp

Barceló Adrover, A., Grimalt Gelabert, M. y Binimelis Sebastián, J. (2015). Implicaciones territoriales, sociales y ambientales de las sociedades de cazadores locales en Mallorca. En J. de la Riva, P. Ibarra, R. Montorio, y M. Rodrigues, (Eds.), XXIV Congreso de la Asociación Española de Geógrafos. Análisis espacial y representación geográfica: innovación y aplicación (pp 1543-1552). Recuperado de http:// congresoage.unizar.es/eBook/trabajos/163_Barcelo\%20Adrover.pdf

Barceló Adrover, A., Grimalt Gelabert, M. y Binimelis Sebastián, J. (2017). Análisis bibliométrico de los estudios geográficos de la caza en España (1978-2015). Boletín de la Asociación de Geógrafos Españoles, 74, 301-332. Recuperado de http://dx.doi.org/10.21138/bage.2456

Barceló Adrover, A., Seguí Campaner, B. y Rengifo Gallego, J.I. (2017). La caza de la cabra salvaje mallorquina en el contexto del turismo cinegético. Ería, 37(2), 233-252. Recuperado de https://doi.org/10.17811/ er.2.2017.233-252

Barrios, E. (2017). Ciclo de vida de un producto y sus estrategias relacionadas. Argentina: Universidad Nacional de la Patagonia Austral

Binimelis Sebastián, J. y Ordinas Garau, A. (2012). Paisatge i canvi territorial en el món rural de les Illes Balears. Territoris, $8,11-28$

Borsellino, L. (2017). El uso de la fotografía y la Ciencia Ciudadana como herramientas para la conservación de la biodiversidad. Revista Photo \& Documento, (3)

British Association for Shooting and Conservation - BASC - (2017). Membership hit a recordbreaking 150.000. Recuperado de https://basc.org.uk/blog/press-releases/latest-news/membershiphits-a-record-breaking-150000/

Brunet Estarellas, P. J. (1978). Aspectes geogràfics i socials de la caça i dels vedats a Mallorca. Treballs de geografia, 35, 25-34. Recuperado de http://ibdigital.uib.es/greenstone/collect/treballsGeografiaVolums/ index/assoc/Treballs/_de_Geog/rafia_19/78v35.dir/Treballs_de_Geografia_1978v35.pdf

Butler, R. (1980). The Concept of a Tourist Area Cycle of Evolution: Implications for Management of Resources". Canadian Geographer, 24 (1), 5-12 
Barceló Adrover, A., Seguí Campaner, B., Guaita Mas, F. (2020): "Planificación y gestión de la caza en Mallorca. El visor de espacios cinegéticos del Consell de Mallorca”, GeoFocus, n 25, p. 121-151. http://dx.doi.org/10.21138/GF.660

Capel Sáez, H. (2010). Geografía en red a comienzos del Tercer Milenio. Por una ciencia solidaria y en colaboración. Scripta Nova. Revista Electrónica de Geografía y Ciencias Sociales, 2010, vol. XIV, num. 313. Recuperado de http://hdl.handle.net/2445/113008

Chic, Ó. (2019). La ciencia ciudadana en el medio marino: Observadores del Mar e Intemares. Recuperado de http://hdl.handle.net/10261/205429

Chinchilla Rodríguez, A. (2015). Ordenación cinegética. Guía metodológica para Proyectos y planes técnicos. Colegio de Ingenieros de Montes, $231 \mathrm{pp}$.

Codinachs, M.; Cots, R.; Guaita, X.; Latorre, M. y Sáez, J. 2013. SITMUN, una plataforma para la gestión territorial municipal. Recuperado de https://www.idee.es/resources/presentaciones/JIIDE13/miercoles/2_SITMUN.pdf

Danby, I. 2017. We love our maps. Shooting and Conservation, the BASC magazine September October 2017. 70-71.

Decreto 506/1971, de 25 de marzo (agricultura), por el que se prueba el reglamento para la ejecución de la Ley de caza de 4 de abril de 1970. BOE, núm. 76 (30/03/1971), pág. 5.108 - 5.118.

Decreto 72/2004, de 16 de julio, por el cual se regulan los planes técnicos de caza y los refugios de caza en las Illes Balears. BOIB núm. 102, (22-07-2004), pág. 29 - 32.

Farfán, M. Ángel; Guerrero, J. Carlos; Real, Raimundo; Barbosa, A. Márcia y J. Mario Vargas (2004): "Caracterización del aprovechamiento cinegético de los mamíferos en Andalucía", Galemys, Boletín SECEM, Jun; 16 (1), pp. 41-59.

Gálvez-Bravo, L., Cassinello, J. (2013). Gestión cinegética y conservación: aspectos ecológicos, problemáticas y retos de futuro. Ecosistemas 22(2):1-5. Doi.: 10.7818/ECOS.2013.22-2.01

García González, M. B. (2019). Posibilidades en Ciencia Ciudadana. Recuperado de https://digital.csic.es/bitstream/10261/192396/1/MB_Garcia_Ciencia_ciudadana_compressed.pdf

Guerra Velasco, Juan Carlos; Fernández Manso, Alfonso; Quintano Pastor, Carmen y Delgado, J.A. (2002): "Integración de información cinegética en un SIG Regional: metodología y aplicación a la Comunidad Autónoma de Castilla y León (España)", en García Cuesta, José Luís, Molina de la Torre, Ignacio y Andrés López, Gonzalo (Coord.): Ciencia y tecnología de la información geográfica en un mundo globalizado: X Congreso del Grupo de Métodos Cuantitativos, Sistemas de Información Geográfica y Teledetección.

Institut Balear d'Estadística. Padrón (cifras de población). Datos anuales, 2018. Recuperado de https://ibestat.caib.es/ibestat/estadistiques/4313a1d1-7f62-4d51-b738-c1558dff6275/e563867b137e-4d3e-a164-4cf16270b51d/es/pad_t1a1_18.px

Jiménez García, Daniel (2007). Paisaje, biodiversidad y gestión sostenible de recursos cinegéticos a escala regional en agrosistemas meditarráneos mediante el uso de tecnologías SIG y GPS. Tesis doctoral. Universitat d'Alacant.

Jover Avellà, G. i Manera Erbina, C. (2009). Producción y productividad agrícolas en la Isla de Mallorca, 1590 - 1860. Revista de Historia Económica 463. Journal of Iberian and Latin American Economic History. Año XXVII. No 3: 463-498

Jover, G. y Manera, C. (2009) "Producción y productividad agrícolas en la Isla de Mallorca, 1590 1860”, Revista de Histórica Económica, Año XXVII. Invierno 2009. № 3: 463-498. 
Barceló Adrover, A., Seguí Campaner, B., Guaita Mas, F. (2020): "Planificación y gestión de la caza en Mallorca. El visor de espacios cinegéticos del Consell de Mallorca", GeoFocus, $n^{\circ}$ 25, p. 121-151. http://dx.doi.org/10.21138/GF.660

Ley 1/1970, de 4 de abril, de Caza. BOE, Núm. 82 (06-04-1970), p. 5.348 - 5.356.

Ley de Caza de 1902.

Ley 3/2013, de 17 de julio, de modificación de la Ley 6/2006, de 12 de abril, balear de caza y pesca fluvial, y modificada per la Ley 6/2007, de 27 de diciembre, de medidas tributarias y económicoadministrativas. BOIB núm. 106, (30-07-2013), pág. 37.046 - 37.068.

Ley 6/2006, de 12 de abril, balear de caza y pesca fluvial. BOIB, núm. 61 (27-04-2006), pág. 42 62 .

López Ontiveros, A. (1992 9. La investigación sobre la actividad cinegética en España: Estado de la cuestión. In: Varios Autores. VI Coloquio de geografía rural. Ponencias. Universidad Autónoma, Madrid. 145-188.

Martín, J., Alonso, F. y Gomariz, F.J. (2011). Desarrollo de un visor cartográfico web para el parque regional de Sierra Espuña. V Jornades de SIG Libre. Servei d'Informació Geogràfica i Teledetecció. Universitat de Girona Recuperado de https://www.researchgate.net/publication/267207399_Desarrollo_de_un_visor_cartografico_web_p ara_el_Parque_Regional_de_Sierra_Espuna

Martín, L. M., Rengifo, J. I. y Sánchez, J. M. (2019). El modelo de caza social: evolución y caracterización en Extremadura. BAGE: Boletín de la Asociación de Geógrafos Españoles, 82, 2793, 1-37. Recuperado de http://dx.doi.org/10.21138/bage.2793

Ministerio de Agricultura, Pesca y Alimentación - MAPA - (2019). Estadística Anual de Caza. Recuperado de https://www.mapa.gob.es/es/desarrollo-rural/estadisticas/Est_Anual_Caza.aspx

Muñoz, M., Barceló, A., Rayó, C., Bernat, M., Barceló, J.M., Castillo, V., Castro, F., Vaquerizas, P.H., Blanco-Aguiar, J.A., Aparicio, F., Seguí, B., Villafuerte, R. (2019 a) Seguimiento y recuperación de las poblaciones de conejo europeo (Oryctolagus cuniculus cuniculus) en Mallorca (Illes Balears) (2017-2019). In: Pons, G.X., Barceló, A., Muñoz, M., del Valle, L. i Seguí, B. (editors). Recerca i gestió dins l'àmbit cinegètic. Mon. Soc. Hist. Nat. Balears, 28: 21-40. ISBN 978-84-09-11001-8.

Muñoz, M., Prohens, C., Rayó, C.M., García, À., Vidal, F.J., Nolla, M., Alomar, C., Barceló, J.M., Bernat, M., Roldán, E., Barceló, A. i Seguí, B. (2019 b). Seguiment poblacional del conill de camp (Oryctolagus cuniculus), llebre (Lepus granatensis) i perdiu roja (Alectoris rufa) a Mallorca. In: Pons, G.X., Barceló, A., Muñoz, M., del Valle, L. i Seguí, B. (editors). Recerca i gestió dins l'àmbit cinegètic. Mon. Soc. Hist. Nat. Balears, 28: 65-88. ISBN 978-84-09-11001-8.

Ordinas, A., y Binimelis, J. (2002). Vindicación de la toponimia como instrumento para el estudio del cambio rural. Rururbanización y neotoponimia en los municipios de Selva e Inca (Mallorca). Los espacios rurales entre el hoy y el mañana, 285-293.

Ortega, T., Seguí, B., Barceló, A., Pons, G. X., Bover, P.; Palmer, M. i Manera, J. (2002). Estudi alimentari del mart (Martes martes L.) a Andratx (Mallorca, Illes Balears. Bolletí Societat d"eHistòria Natural de les Balears, 15: 199-216.

Pérez Carral, Cristina (1997). Ordenación silvopastoral de monte Mediterráneo para la caza del ciervo. Bases ecológicas y usos de sistemas de información geográfica. Aplicación al centro "Los Quintos de Mora" (Los Yébenes, Toledo). Tesis doctoral. Universidad Politécnica de Madrid. 
Barceló Adrover, A., Seguí Campaner, B., Guaita Mas, F. (2020): "Planificación y gestión de la caza en Mallorca. El visor de espacios cinegéticos del Consell de Mallorca", GeoFocus, $n^{\circ}$ 25, p. 121-151. http://dx.doi.org/10.21138/GF.660

Pons, G.X., Barceló, A., Muñoz, M., del Valle, L. i Seguí, B. (editores). (2019). Recerca i gestió dins l'àmbit cinegètic. Mon. Soc. Hist. Nat. Balears, 28: 1-215.

Portal Valenzuela, B. F., Espinoza Ramírez, J. C., y Carreño Zúñiga, M. (2014). Impacto de la demanda de un turismo social en la sustentabilidad de la actividad en el balneario de El Quisco, Provincia de San Antonio-Chile. Investigaciones geográficas, (83), 102-115.

Prohens, C. i Seguí, B. (2013) Censos de fauna cinegètica Mallorca 2012. In: Pons, G.X., Ginard, A. i Vicens, D. (ed.). VI Jornades de Medi Ambient de les Illes Balears. Ponències i Resums. Soc. Hist. Nat. Balears. Palma de Mallorca. 171 - 172.

Real Decreto 137/1993, de 29 de enero, por el que se aprueba el Reglamento de Armas. BOE núm. 55, de 5 de marzo de 1993, páginas 7016 a 7051.

Rodríguez-Teijeiro, J.D., García, A., García-Galea, E., Jiménez-Blasco, I., Torres, A., Barceló, A., Muñoz, M., Vidal, F.J., Puigcerver, M. and Seguí, B. (2019) Dinàmica de la població de guàtlera a l'illa de Mallorca i comparació amb les poblacions del nord-est de la península Ibèrica. In: Pons, G.X., Barceló, A., Muñoz, M., del Valle, L. i Seguí, B. (editors). Recerca i gestió dins l'àmbit cinegètic. Mon. Soc. Hist. Nat. Balears, 28: 51-64. ISBN 978-84-09-11001-8.

Sancho, M. y Monzón, M. (2018). "El mapeado como herramienta en la regeneración de conjuntos de viviendas sociales". "The mapping as a tool in the regeneration of social housing groups". Ciudad y formas urbanas. Perspectivas transversales, Volumen 8. Formas urbanas y mapping, II Congreso Internacional ISUF-H, Zaragoza 2018, 135 - 146.

Santandreu, J.; Seguí, B.; Palmer, M. y Pons, G.X. (2002). Estudi dels tords (Turdus philomelos L.) hivernants a les Balears a partir de taules de caça. Descripció de la pressió de caça. Aspectes poblacionals. Conselleria de Medi Ambient. Govern de les Illes Balears. Inédito.

Scolopax Sin Fronteras. [Consulta: 25-07-2019]. Disponible en http://rtvs.ccbp.org/

Secco, F. Z., da Cunha, C. F., Spers, E. E., Galeano, R., \& da Silva, R. R. C. (2016). Etapas de la planificación estratégica de marketing y el ciclo de vida organizacional. Estudio en una empresa de gestión familiar. Invenio, 19(36), 65-87.

Seguí, B., Sanz, A. (ed), Barceló, A., García, A., Santandreu, J. i Vidal, J. (2014). Boc Balear, cuatro milenios de historia, diez años de homologación. Consell de Mallorca, Departament de Medi Ambient con la colaboración del Capítulo Balear del SCI, del Safari Club Internacional y El Premio Ullmann para Trofeos Europeos de Caza Mayor, Palma. 253 pp.

Taborda Barroso, M., Oria, J., y Vázquez, A. (2018). Leaflet: visor cartográfico en gestión de especies silvestres: Lince ibérico en Extremadura. Recuperado de http://hdl.handle.net/10256/15718

Ventura, J. (2016). "Identificación e inventario de potenciales glaciares rocosos activos en los Pirineos mediante fotointerpretación en visores cartográficos 2D y 3D: primeros resultados". Polígonos. Revista de Geografía, núm. 28, 95-122.

Walteros, J. (2019). Biomonitoreo acuático participativo, una estrategia para promover la ciencia ciudadana. Bio-grafía, 1235-1245. 
Barceló Adrover, A., Seguí Campaner, B., Guaita Mas, F. (2020): "Planificación y gestión de la caza en Mallorca. El visor de espacios cinegéticos del Consell de Mallorca”, GeoFocus, $n^{\circ} 25$, p. 121-151. http://dx.doi.org/10.21138/GF.660

Agradecimientos

A Sergi Martino, Aina Bistuer (EPD), Consuelo Novo, María Muñoz, Elena Tur, Isabel Gómez, Joan Ferretjans, Àngel García, Antonia Rosselló, Pere Garcias, Javier Vidal, Margalida Garau, Miquel Roig, Sebastià Ferragut, Eduardo Somed, Miquel Garau, Gero Corró, Núria Navarro, Tomeu Trobat, Ramon Valero, Fernando San Nicolás, Antonio Mena, Pablo Ruíz y Josep Bergas, personal técnico, administrativo y de vigilancia del Servei de Caça del Departamento de Promoción Económica y Desarrollo Local del Consell de Mallorca por su ayuda y colaboración en todo momento.

Al Servicio de Informática del Departamento de Hacienda y Función Pública, por su asesoramiento técnico.

A Joan Miquel Genovard, Cati Pol y Cosme Prohens, por su gran labor en la digitalización de cotos y elaboración de las bases de datos del SIG de Caza.

A la Dirección Insular de Relaciones Institucionales y Proyectos del Departamento de Presidencia del Consell de Mallorca por facilitar la elaboración de este trabajo.

A la Federación Balear de Caza, la Asociación Balear de Entidades de Caza, clubs y asociaciones de ámbito cinegético por su apoyo.

A Félix Escalas, Bartomeu Alcover y al personal técnico del Servei d'Informació Territorial de les Illes Balears por su ayuda en la gestión de las capas de caza en la IDEIB.

A Carlos Sánchez de Fundación Artemisan por sus aportaciones. 
